
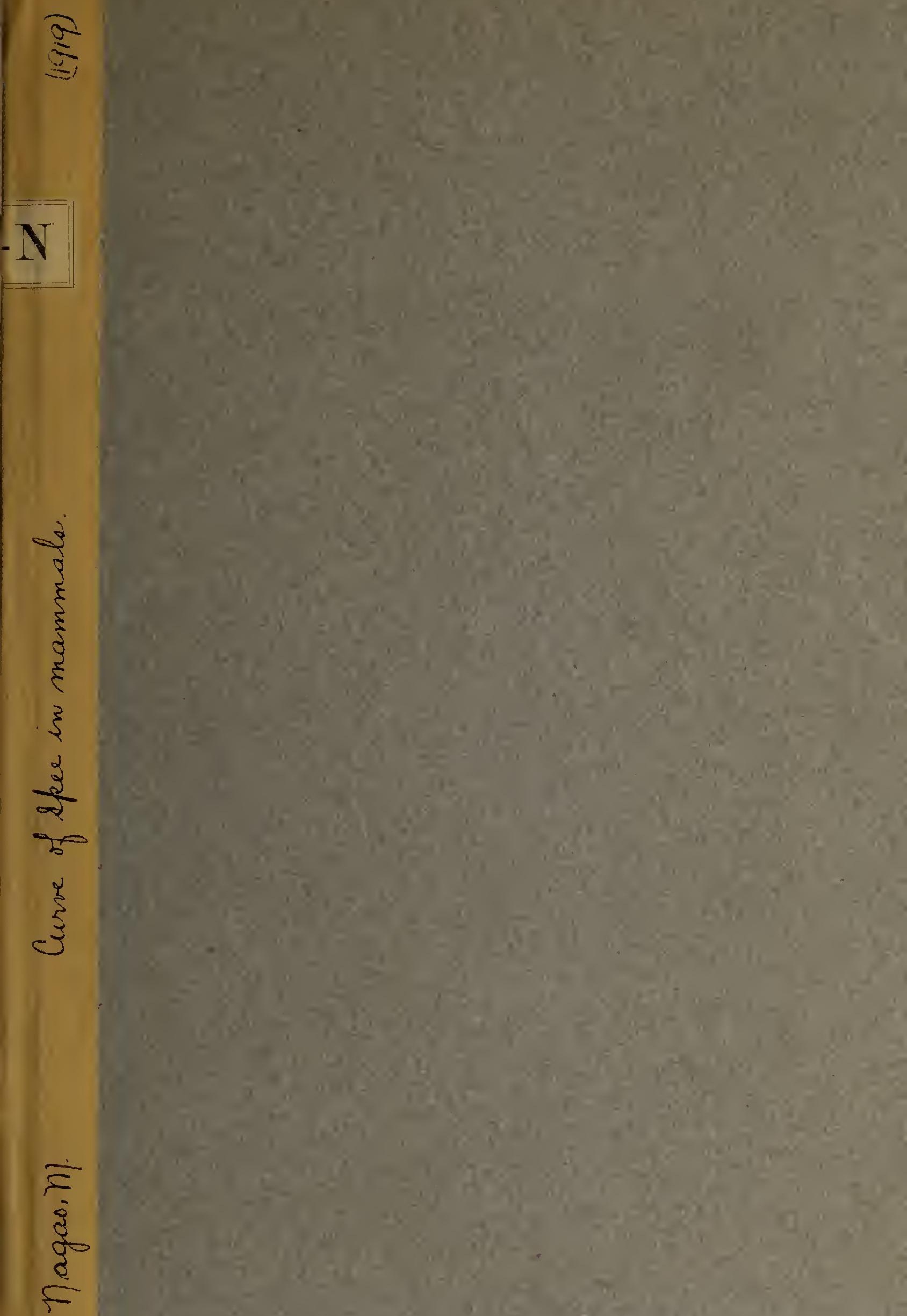
HARVARD UNIVERSITY.

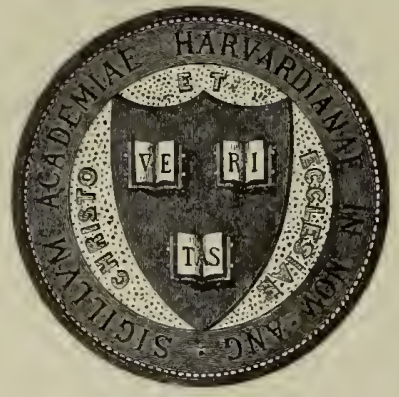

\section{LIBRARY}

OF THE

MUSEUM OF COMPARATIVE ZOÖLOGY

$$
\begin{aligned}
& 65,746 \\
& \text { GIFT OF }
\end{aligned}
$$

William M. Wheeler

Morember 6. 1925. 


$$
65,746 \quad 110 \mathrm{~V} 61925
$$

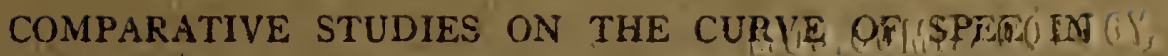

MAMMALS, WITH A DISCUSSION OF ITS RELATION $/$ \& TO THE FORM OF THE FOSSA MANDIBULARIS

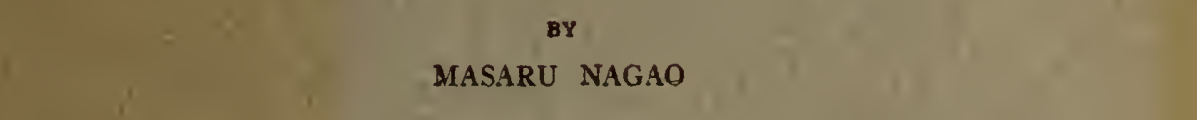

(Dental Hospital of tae Departuent of Edccation, Tozyo, Japan; also Wistar I.istitute of ANATOMY AND BloLosy, UNIVERsity of

Pennsylyanla, Phil.adelphia)

\section{REPRINTED FROY}

THE JOURNAI, OF DENTAL RESEARCH

Vol. i, No. 2, JuNe, 1919 



\title{
COMPARATIVE STUDIES ON THE CURVE OF SPEE IN MAMMALS, WITH A DISCUSSION OF ITS RELATION TO THE FORM OF THE FOSSA MANDIBULARIS
}

\author{
MASARU NAGAO
}

Dental Hospital of the Department of Education, Tokyo, Japan

From the Wistar Institute of Anatomy and Biology, Philadelphia

\section{CONTENTS}

I. Introduction. ..................................... 159

II. Material used in these studies............................. 161

Fxamination of the material.......................... 161

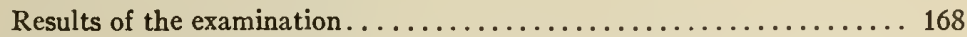

III. Selection of the standards to be used for the purpose of comparing the curve of Spee given by various mammals ...................... 170

IV. Determination of the length of radius ........................ 171

V. Determination of the inclination of the fossa mandibularis............. 178

VI. Determination of the dental and gnathic indices................. 182

VII. Determination of the angle formed between the line of articulation and the

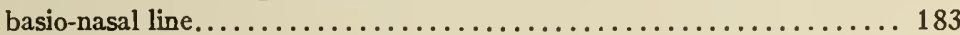

VIII. Comparative study of the curve of Spee...................... 184

The author's own data.............................. 184

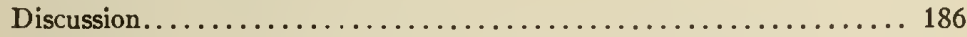

Relation between the "center angle" of the curve of Spee and the angle of the line of articulation to the basio-nasal line. . . . . . . . . . . . . 189

IX. Relation between the form of the fossa mandibularis and the curve of Spee.. 191

X. Summary......................................... 199

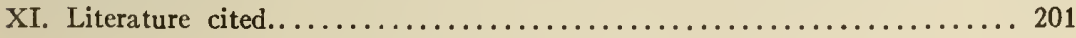

\section{INTRODUCTION}

In 1890 Spee described some peculiarities of the occlusion of the bicuspids and molars, which are closely related to the form, and especially to the inclination, of the fossa mandibularis and the manner of movement of the mandible, and which have an important bearing upon the efficiency of these teeth as masticatory organs. A free translation of his initial statement follows:

"If a curved line be drawn touching the summits of the buccal cusps of the upper or lower teeth from first bicuspid to third molar, it will more or 
less accurately correspond to the arc of a circle with its convexity downwards. This curve varies in different individuals. If, in a skull with typical denture, it is continued in a projection of the jaw upon the vertical sagittal plane, it touches the anterior face of the articular surface of the condyle. This is the most ideal form. In the case of man, the center of this curve lies behind the crista lacrymalis posterior and on the line bisecting the horizontal plane passing through the orbit."

The curve thus formed has been called "the curve of Spee" or "the compensating curve," and was considered by Spee to have important relations to the mechanism of mastication.

Fick (1911) doubted the relation stated to exist between this curve and the movement of the lower jaw, but he did not give any evidence to substantiate his contention (see section viii). This view of Fick has, however, not been further examined by other investigators and the conclusion of Spee is therefore generally accepted in its entirety. Since the conclusion of Spee has a very important bearing on the mechanism of mastication, I thought it worth while to reinvestigate the curve of Spee and if possible to determine whether Fick's objection is in any way justified.

As a first step an attempt was made to determine the nature of the curve shown by various mammals when the line is drawn touching the summits of the buccal cusps of the bicuspids and molars. From the curve thus obtained, the variations in the degree of the curvature shown by different species of mammals were determined for the purpose of a comparative anatomical study. At the same time, the degree of the inclination of the fossa, the gnathic index, dental index, and the angle between the line of articulation and basio-nasal line, were all measured directly on the skulls of many mammals, in order to determine whether any of these are related to the formation of the curve of Spee; indeed, Spee himself considers that the inclination of the fossa and the gnathic index have such a relation. Finally, using these data, the relation of this curve to the masticatory movements of the jaws is discussed.

This work was begun in July, 1917, and completed in the earlier part of 1918 at The Wistar Institute of Anatomy and Biology. It gives me great pleasure to acknowledge my indebtedness to Dr. Greenman, Director of the Institute, for his generosity in permitting 
me to study at the Institute, and in furnishing me with all the material and instruments necessary for the present investigation. Also I wish to express my thanks and gratitude to Dr. Turner and Dr. Hatai, for their kindness and interest shown me during the course of this investigation and in the revision of this paper.

\section{MATERIAL USED IN THESE STUDIES}

The skulls used for this study belong to the collection in the museum of the Wistar Institute of Anatomy and Biology, and had been prepared by the usual method for the purpose of exhibition. Nearly 120 skulls, representing several orders of mammals, and apparently of adult age, as shown by the presence of the well developed third molars, were available. On account of the difficulty in getting human skulls which show the ideal occlusion, only fourteen human skulls out of this series were utilized, though for the other orders of mammals, this selection was easier. In the cases of Porcus babyrussa, Lama huanacho, Cervulus muntjac, and Rhinoceros, however, I found only one specimen for each species.

In this paper I have followed the classification used by Brehm in his "Tierleben" (third edition, 1890). There are some orders of mammals which I did not study owing either to the difficulty in getting specimens, or because of the absence in them of the curve of Spee. The name, the locality (or race in the case of man), and the sex of each individual, as well as the museum catalog number, are given in table 1.

\section{Examination of the material}

Preliminary to the study of the curve of Spee, I attempted to determine the following two points on every skull used.

1. Whether or not the curved line, which is drawn touching the summits of the buccal cusps of the bicuspids and molars, would correspond to the arc of a circle with its convexity downwards.

2. If so, whether the extension of the curved line backwards touches the anterior face of the articular surface of the condyle?

I shall first present briefly the various methods employed for these determinations. 
TABLE 1

A designation of the kinds and number of skulls used in these studies, and an indication of the museum number, locality (or race, in the case of man), and sex of each skull. Arranged according to the zoological order adopted by Brehm

\begin{tabular}{|c|c|c|c|}
\hline \multicolumn{2}{|l|}{ SKULLS } & \multicolumn{2}{|l|}{ ANIMALS } \\
\hline Types & $\begin{array}{c}\text { Museum } \\
\text { number }\end{array}$ & Locality (or race) & Sex \\
\hline \multicolumn{4}{|l|}{ Primiates: } \\
\hline \multirow{13}{*}{ Homo (man) } & 800 & $?$ & $?$ \\
\hline & $4237 *$ & $\begin{array}{c}\text { Negro } \\
?\end{array}$ & o \\
\hline & 5419 & Eskimo & $?$ \\
\hline & 4284 & $\begin{array}{l}\text { LSKmino } \\
\text { Negro }\end{array}$ & ? \\
\hline & 15700 & Peruvian & 9 \\
\hline & 15803 & Peruvian & $?$ \\
\hline & 15863 & Peruvian & ? \\
\hline & 15779 & Peruvian & ? \\
\hline & 15689 & Peruvian & ? \\
\hline & 15613 & $?$ & ? \\
\hline & 15640 & Peruvian & ? \\
\hline & 15774 & Peruvian & ? \\
\hline & 15586 & Peruvian & ? \\
\hline \multirow[t]{7}{*}{ Simia satyrus (orang utan) } & 5646 & Borneo & $0^{7}$ \\
\hline & 2222 & Borneo & $?$ \\
\hline & 1563 & Borneo & ? \\
\hline & 2170 & Borneo & ? \\
\hline & 2172 & Borneo & $?$ \\
\hline & 7064 & Borneo & $?$ \\
\hline & 2223 & Borneo & $\sigma^{\pi}$ \\
\hline \multirow[t]{5}{*}{ Hylobates mülleri (gibbon) } & 6157 & Borneo & $0^{\pi}$ \\
\hline & 690 & Borneo & $0^{\pi}$ \\
\hline & 3666 & Borneo & $\sigma^{7}$ \\
\hline & 12074 & Borneo & $\sigma^{7}$ \\
\hline & 699 & Borneo & $\sigma^{7}$ \\
\hline \multirow[t]{3}{*}{ Macacus cynomolgus (macaque monkey) } & 1893 & Borneo & $0^{x}$ \\
\hline & 1889 & Borneo & $\sigma^{\top}$ \\
\hline & 1891 & Borneo & $0^{7}$ \\
\hline \multirow{9}{*}{$\begin{array}{l}\text { Semnopithecus femoralis (sacred monkey } \\
\text { hocnoomaún) }\end{array}$} & & & \\
\hline & 2989 & Borneo & ? \\
\hline & 3801 & Borneo & 0 \\
\hline & 2657 & Borneo & 0 \\
\hline & 2925 & Borneo & $\begin{array}{l}7 \\
0\end{array}$ \\
\hline & 2920 & Borneo & 7 \\
\hline & 2923 & Borneo & $\sigma^{\prime}$ \\
\hline & 3000 & Borneo & $\sigma^{\prime}$ \\
\hline & 2660 & Borneo & 우 \\
\hline
\end{tabular}

* This specimen belongs to Dr. Stotsenburg. 


\begin{tabular}{|c|c|c|c|}
\hline \multicolumn{2}{|l|}{ SKULLS } & \multicolumn{2}{|l|}{ ANIMALS } \\
\hline Types & $\begin{array}{c}\text { Museum } \\
\text { number }\end{array}$ & Locality (or race) & Sex \\
\hline \multicolumn{4}{|l|}{ Primates-Continued } \\
\hline \multirow[t]{5}{*}{ Nasalis larvatus (Kahaŭ monkey) } & 2263 & Borneo & q \\
\hline & 2267 & Borneo & q \\
\hline & 1834 & Borneo & $\sigma^{7}$ \\
\hline & 2261 & Borneo & \% \\
\hline & 6156 & Borneo & q \\
\hline \multirow[t]{5}{*}{ Macacus nemestrinus (macaque monkey) } & 5872 & $?$ & q \\
\hline & 5861 & ? & 8 \\
\hline & 5660 & $?$ & 8 \\
\hline & 5860 & $?$ & $\sigma^{7}$ \\
\hline & 5652 & Penang & \& \\
\hline \multicolumn{4}{|l|}{ CARNIVORA: } \\
\hline \multirow[t]{2}{*}{ Canis familiaris (dog) } & 6141 & ? & ? \\
\hline & 6145 & ? & ? \\
\hline \multirow[t]{2}{*}{ Felis leo (lion) } & 6201 & ? & ? \\
\hline & 6196 & $?$ & $?$ \\
\hline Felis catus (cat) & 6198 & Texas & $?$ \\
\hline \multirow{5}{*}{ Procyon lotor (raccoon) } & 2278 & ? & $?$ \\
\hline & 5970 & ? & $?$ \\
\hline & 5976 & $?$ & $?$ \\
\hline & 6006 & $?$ & $?$ \\
\hline & 6008 & $?$ & $?$ \\
\hline \multirow{11}{*}{$\begin{array}{l}\text { RODENTIA: } \\
\text { Fiber zibethicus (muskrat) }\end{array}$} & & & \\
\hline & 5902 & Pennsylvania & $?$ \\
\hline & 5921 & Pennsylvania & $?$ \\
\hline & 5884 & Pennsylvania & $?$ \\
\hline & 5916 & Pennsylvania & $?$ \\
\hline & 5883 & Pennsylvania & $?$ \\
\hline & 5918 & Pennsylvania & $?$ \\
\hline & 5915 & $?$ & $?$ \\
\hline & 5903 & $?$ & $?$ \\
\hline & 5908 & $?$ & $?$ \\
\hline & 5889 & $?$ & $?$ \\
\hline \multirow[t]{5}{*}{ Cavia cutleri (guinea pig) } & 5940 & $?$ & $?$ \\
\hline & 5954 & ? & ? \\
\hline & 5549 & $?$ & $?$ \\
\hline & 5562 & $?$ & $?$ \\
\hline & 5569 & ? & $?$ \\
\hline \multicolumn{4}{|l|}{$\begin{array}{l}\text { Perissodactyla: } \\
\text { Rhinoceros }\end{array}$} \\
\hline Rhinoceros & 4661 & $?$ & $?$ \\
\hline \multirow{3}{*}{$\begin{array}{l}\text { ARTIODACTYLA: } \\
\text { Camelus bactrianus (bactrian camel) }\end{array}$} & & & \\
\hline & 5657 & $\begin{array}{l}\text { Zoological Gar- } \\
\text { den, Phila- } \\
\text { delphia }\end{array}$ & \% \\
\hline & 6266 & $\begin{array}{l}\text { Zoological Gar- } \\
\text { den, Phila- } \\
\text { delphia }\end{array}$ & $\sigma^{\pi}$ \\
\hline
\end{tabular}


TABLE 1-Concluded

\begin{tabular}{|c|c|c|c|}
\hline \multicolumn{2}{|l|}{ SKOLLS } & \multicolumn{2}{|l|}{ ANIMALS } \\
\hline Types & $\begin{array}{l}\text { Museum } \\
\text { number }\end{array}$ & Locality (or race) & Sex \\
\hline \multicolumn{4}{|l|}{ ARTIODACTYLA-Continued } \\
\hline Lama huanacho (guanacho) & 5632 & $\begin{array}{l}\text { Zoological Gar- } \\
\text { den, Philadel- } \\
\text { phia }\end{array}$ & ? \\
\hline \multirow[t]{7}{*}{ Rangifer tarandus (caribou) } & 5497 & Alaska & 운 \\
\hline & 5485 & Alaska & $0^{7}$ \\
\hline & 5479 & Alaska & 우 \\
\hline & 5477 & Alaska & 우 \\
\hline & 5480 & Alaska & ? \\
\hline & 5484 & Alaska & क \\
\hline & 5475 & Alaska & q \\
\hline \multirow[t]{2}{*}{ Tragulus javanicus (musk deer) } & 6045 & Borneo & ? \\
\hline & 6091 & Borneo & ? \\
\hline Cervulus muntjac (deer) & 6182 & Borneo & $q$ \\
\hline \multirow[t]{5}{*}{ Sus barbatus (boar) } & 2210 & Borneo & $?$ \\
\hline & 6163 & $?$ & $?$ \\
\hline & 1569 & Borneo & $\sigma^{7}$ \\
\hline & 2853 & Borneo & $?$ \\
\hline & 6150 & $?$ & ? \\
\hline Porcus babyrussa (babirusa) & 4773 & Celebes Island & $0^{7}$ \\
\hline \multirow[t]{4}{*}{ Dicotyles sp. (peccary) } & 7451 & $?$ & $?$ \\
\hline & 6202 & ? & ? \\
\hline & 6207 & $?$ & ? \\
\hline & 2199 & Brazil & ? \\
\hline \multicolumn{4}{|l|}{ MARSUPIALIA: } \\
\hline \multirow[t]{4}{*}{ Didelphys marsupialis (opossum) } & 5971 & $?$ & $?$ \\
\hline & 6005 & ? & ? \\
\hline & 6025 & ? & $?$ \\
\hline & 6273 & ? & ? \\
\hline
\end{tabular}

Spee stated in his paper ${ }^{-}(1890)$ that, as the series of teeth in the adult human skull lies in a plane not deviating greatly from the sagittal plane of the skull (the smooth line $P Q$,-figure 1-connecting the summits of the buccal cusps of the bicuspids and molars having an angle 15 to 20 degrees to the sagittal plane, $O P$, of the skull), it follows that the relative position of the teeth does not deviate from their true relation if they are projected upon the sagittal plane with a large lens. He made photographs of skulis, setting the photographic plates parallel to the sagittal plane, and studied the curve on the photographs. 
This method of Spee is open, however, to some criticism and, beginning with human material, I have employed the following projection method which seems to be better adapted for the purpose.

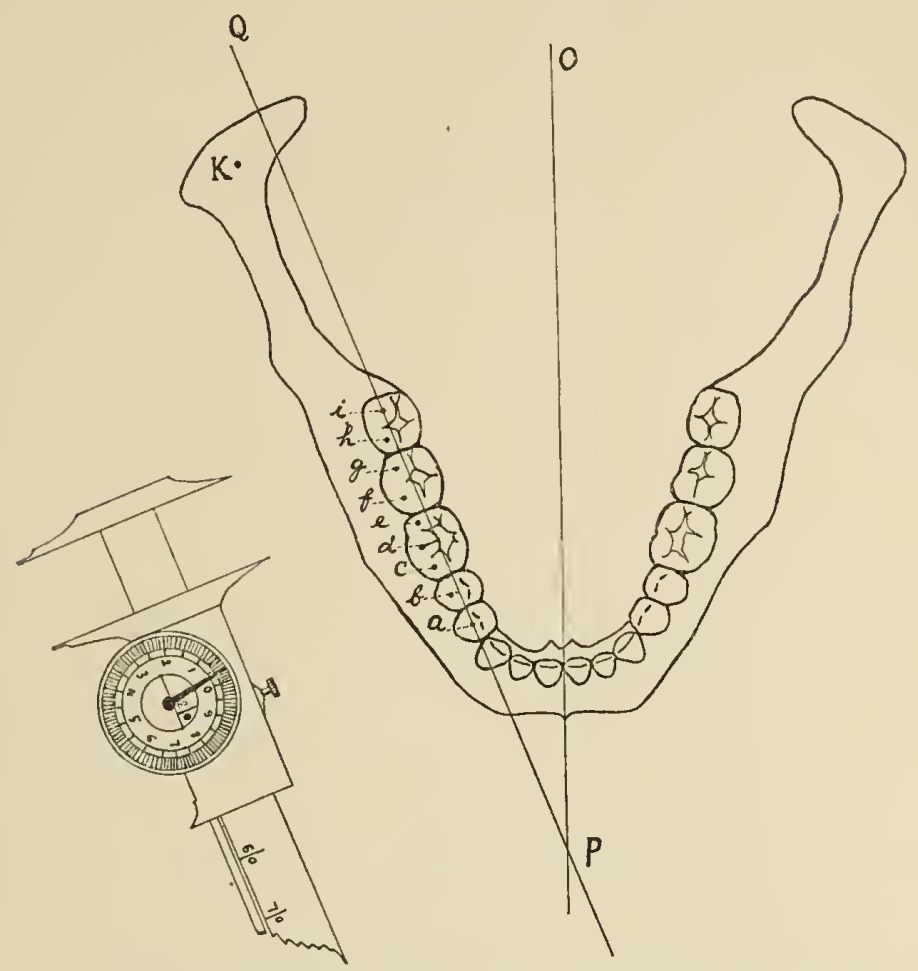

Fig. 1. Diagram Showing the Plane of Projection and also the Form of Callipers used for the Measurements

$O P$, projection plane used by Spee; $P Q$, projection plane used by the author; $a, b, c$ . . . and $i$, each buccal cusp from the first bicuspid to the third molar; $K$, middle point of the condyle.

The plane, on which the cusps are to be projected, has been so selected that it is perpendicular to the horizontal plane (on which the lower jaw ${ }^{1}$ rests), and parallel to the line $P Q$-figure 1 -which connects the buccal cusp of the first bicuspid and the disto-buccal

${ }^{1}$ For the preliminary examination of the curve of Spee, I used exclusively the lower jaw, because it is easier to manipulate in applying my method. 
cusp of the most posterior molar. Instead of projecting the positions of each buccal cusp of the bicuspids and molars perpendicularly on this plane, I have measured the distances between each successive cusp and also the height of each cusp from the horizontal plane (on which the lower jaw rests). These two sets of measurements were plotted, taking the former for the abcissae and the latter for the ordinates. The desired curve was finally obtained by connecting the tips of the ordinates as shown in figure 2. 'This method of selecting the projection plane has some advantage when compared with that

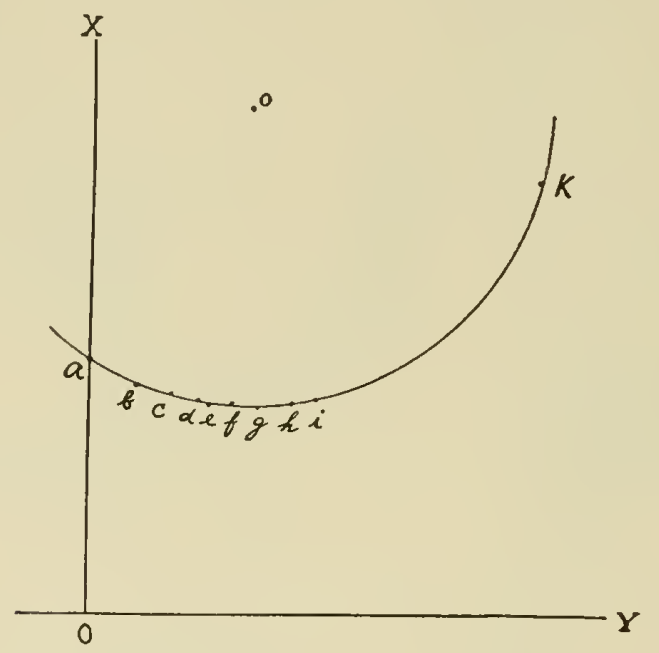

fig. 2. Showing the Projection Points of Each Buccal Cusp and the Mmole Point of the Condyle in the Case of the Orang Utan

Specimen 2170 , right. $O X$, ordinate; $O Y$, abcissa.

of Spee, because the relative positions of the cusps of the teeth are better represented than when they are projected on the sagittal plane.

My method, however, is not entirely beyond criticism owing to the slight curvature of the dental arch, although the curvature of the dental arch at the region of the bicuspids and molars is insignificant, amounting to not more than 3 to $4 \mathrm{~mm}$. between the arch and its chord, in the case of the human skull. Moreover, in skulls of some other mammals, e.g., the orang utan and the peccary, this curvature is practically zero. The method adopted by me does not distort the 
normal relation to any great extent and $I$ have therefore employed the method throughout the course of this investigation. For convenience of measurement the buccal cusps of the lower teeth and the middle point of the anterior face of the articular surface of the condyle have been designated individually from before backwards by letters of the alphabet, thus: $a$ for first bicuspid, $b$ for second bicuspid, $c, d, e$ for first molar, $f, g$ for second molar, $h, i$ for third molar, and $K$ for condyle ( $f i g .1$ ).

There are several mammals to which the same designation cannot be applied on account of differences between their dental formula and that of man. Still another exception is found in the case of the opossum, owing to the unequal length in that form of the mesiobuccal cusp and disto-buccal cusp of the molar; the latter being twothirds the length of the former. When the teeth are in occlusion, the disto-buccal cusps of the lower teeth are in contact with their antagonists, while the mesio-buccal cusps enter between the two cusps of the upper teeth. I therefore made the measurement only on the disto-buccal cusps, because in such instances it appears to me more reasonable to take the cusps which give contact with their antagonists, since these cusps alone have real importance in the process of occlusion. The lower jaw was placed on a straight line drawn on the table in such a way that all of the cusps of these teeth are on that line when seen from above. Then the distances between $a$ and $b$, $b$ and $c$, etc., were directly measured to $0.1 \mathrm{~mm}$., the points of the callipers being held in a line parallel to the base-line on the table (fig. 1). As for the distance between $i$ and $K$, I measured this holding the points of the callipers parallel to the projection plane $(Q P)$, but not necessarily parallel to the horizontal plane (or base-line). These measurements were entered as the abcissae on a sheet of paper which represents the projection plane.

The values of ordinates corresponding to the abcissal values were determined by the following method. The jaw was placed on the table, and the distance between the cusps and the table were measured to $0.1 \mathrm{~mm}$. by sliding a cross-bar, which is attached to a rod standing perpendicular to the table, until it touched the top of the cusp. The distances for the cusps as thus measured were entered as ordinates on the same sheet of paper. 
The position of $K$ was determined by the following method. Since the distance between the points $K$ and $i$ had been already determined, as well as the vertical distance of the point $K$ from the base-line, the position of $K$ corresponds to the point of intersection made by the arc drawn by the radius $i K$ (the point $i$ being taken as the center of the arc) and by the vertical height of $K$ along the abcissal line. Finally a curve was drawn passing through as many of the points as possible in order to determine whether or not the curve thus obtained is a circle. If the curve was a circle, the second question was whether or not this circle would pass through (or nearly through) the point $K$.

The foregoing method cannot be applied to the jaw of the muskrat on account of the difficulty in making the measurements on a specimen of such small size (nasion-basion diameter about $4 \mathrm{~cm}$., the total length of the teeth ${ }^{2}$ about $1.5 \mathrm{~cm}$.). Therefore I made use of the following device: a small piece of paper $(2.5 \mathrm{~cm}$. by $1.0 \mathrm{~cm}$.) was placed against the lateral side of the teeth and was rubbed with a pencil in order to trace the positions of the buccal cusps of the teeth. The positions of the cusps thus obtained were transferred to another sheet of paper by piercing these points with a needle. In order to determine the position of the point $K$, first the distance between the disto-buccal cusp of the first bicuspid and point $K$ (on the plane of projection), and the distance between the disto-buccal cusp of the most posterior molar and point $K$, were determined. The point of intersection made by the two arcs, drawn with these two measurements as radii and the two corresponding points (first bicuspid and the most posterior molar) as the centers, is the desired point $K$.

\section{Results of the examination}

All the skulls I have examined may be arranged in four groups according to the form of the curve which was obtained by connecting the summits of the buccal cusps of the bicuspids and molars.

1. The group of skulls, in which the curved line corresponds to the arc of a circle, and touches at the same time the anterior face of the articular surface of the condyle or $K$. To this group belong man,

\footnotetext{
2 The total length of the teeth means the distance from the mesial aspect of the first bicuspid to the distal aspect of the most posterior molar, all in situ.
} 
Simia satyrus, Hylobates mülleri, Macacus cynomolgus, Nasalis larvatus, Semnopithecus femoralis, Macacus nemestrinus, Rhinoceros, Camelus bactrianus, Lama huanacho, Rangifer tarandus, Porcus babyrussa and Dicotyles (sp.).

2. The group of skulls in which the curved line corresponds to the arc of a circle but does not touch the anterior face of the articular surface of the condyle or $K$. To this group belong the muskrat and the opossum.

3. The group of skulls in which the curved line possesses several maxima, thus forming an undulating curve. Most carnivora, Tragulus javanicus and Cervulus muntjac belong to this group.

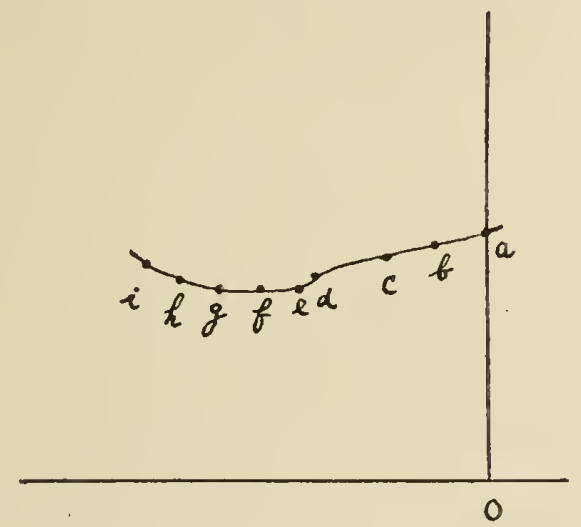

Fig. 3. Showing the Projection of Each Buccal Cusp of the Bicuspids and Molars IN THE CASE OF THE RACCOON

The curved line connecting the points of projection shows an undulation

The existence of this kind of curve was evidently unnoticed by Spee, and it may be worth while, therefore, to describe it more in detail. As an example the curve given by the jaw of a Procyon lotor (raccoon), specimen 6008, is taken. The raccoon which belongs to the family of the Procyonidae, has the following dental formula:

$$
I \frac{3-3}{3-3} \quad C \frac{1-1}{1-1} \quad P M \frac{3-3}{3-3} \quad M \frac{3-3}{3-3}=40
$$

As is shown in figure 3 the line connecting the posterior half with the front half undulates owing to a slight dip, especially at the first 
molar. This phenomenon is probably produced by the failure of the upper and lower bicuspids of the raccoon to occlude closely in the living specimen.

4. The group of skulls in which the arrangement is best represented by a straight line. This kind of curve is met with in the jaw of Sus barbatus (wild pig). Some individual variations were noted among the skulls belonging to this species. Among five skulls of Sus barbatus examined by me, specimens 2210,1569 , and 6150 , have shown a slight curvature with its convexity downwards, while specimen 2853 has the convexity upwards.

III. SELECTION OF THE STANDARDS TO BE USED FOR THE PURPOSE OF COMPARING THE CURVE OF SPEE GIVEN BY VARIOUS MAMMALS

In the preceding section it was shown that in some species of mammals the projection of the buccal cusps of the bicuspids and molars upon a plane forms the arc of a circle. These points lie in the same cylindrical surface, as pointed out by Spee; and the line connecting them, when projected, has been designated "the curve of Spee" by subsequent writers. Since the precise form of the curve of Spee is not always the same, it has been my purpose to find some convenient standard by the use of which the differences can be expressed quantitatively. For this purpose Spee himself (1890) selected the length of the radius of his curve and the results of his observation are given by him in a chapter entitled: "Specielle Befunde an verschiedenen Gebissen." This method of comparison is valuable when the degrees of the curvature of the various curves of Spee are compared with each other. I have therefore followed the principle of Spee and determined the radius of the circle in order to determine the degree of curvature.

Since the curve of Spee is obtained by connecting the summits of the cusps of the bicuspids and molars, the length of the arc cannot be represented by the radius alone. The full form of the curve of Spee in any instance is determined by both its radius and the length of the arc. It is thus clear that in order to make a comparison of the curve of Spee as given by various mammals, we need, besides the radius, which represents the curvature at any point, also the length of the 
arc. With this in mind, the number of degrees representing the angle which subtends a given length of the arc was determined by the following formula:

$$
\operatorname{Sin} \frac{A}{2}=\frac{\text { Chord }}{2 r}
$$

where $A$ represents the angle and $r$ the radius.

In the above formula the radius is given as the measure of the curvature and at the same time the length of the chord is given instead of the arc - the length of the chord being proportional to the length of the arc--and thus the former may be substituted for the latter. We may therefore consider that the angle $A$ may be taken to represent both the length of the radius and the length of the arc. The angle $A$, called "the center angle," and its metlod of determination will now be presented.

\section{DETERMINATION OF THE LENGTH OF RADIUS}

We have already stated that in the cylinder surface lies the part of the circle which passes through each cusp of the bicuspids and molars and the middle point of the anterior face of the articular surface of the condyle. It is possible to determine the length of the radius of any given circle or arc from the three points taken on the circumference by means of the formula on page 172 . The three points $a, h$, and $K$, from the buccal cusps of the bicuspids and molars and the middle point of the anterior face of the articular surface of the condyle, would be preferable, since the distances between adjacent points should be as great as possible for the sake of exact measurements. I have however chosen the point $h$ instead of the point $i$, because the point $i$ in the third molar is not only absent in some cases, but also shows great variation. Speaking more precisey, the mesiobuccal cusp in the most posterior molar was chosen for the present purpose instead of the disto-buccal cusp. For measuring the constants $\alpha(a h), \beta(h K)$ and $\gamma(a K)$ on the skull ( $f g$ 4), the directions which were given in the preceding section should always be followed. It must be emphasized here again that the circle, and the triangle which was formed connecting the three points, were both projected upon the 
same plane. To obtain the radius ( $r$ ) from the constants $\alpha, \beta$, and $\gamma$, the following formula was used:

The radius $(r)$ of the circle circumscribed about the triangle of area ( $t$ ) equals $\alpha \beta \gamma / 4 t$. But from Hero's formula:

$$
\begin{aligned}
\text { Area }(t) & =\sqrt[2]{S S_{1} S_{2} S_{3}} \\
\text { If } S & =\frac{1}{2}(\alpha+\beta+\gamma), \text { then } \\
S_{1} & =S-\alpha \\
S_{2} & =S-\beta \\
S_{3} & =S-\gamma \\
\therefore \operatorname{radius}(r) & =\alpha, \beta, \gamma / 4 \sqrt[2]{S S_{1} S_{2} S_{3}}
\end{aligned}
$$

When the curved line did not touch the anterior face of the articular surface of the condyle $(K)$, as in the case of the muskrat or opossum, some other point than $K$ was taken, and the length of the radius obtained from the triangle as in the previous cases, or directly by the use of compasses.

The data obtained from these determinations are given in tables 2 to 18 .

Tables 2 to 16 give, for each species, the values of $\alpha, \beta$, and $\gamma$ (measured directly on the skull); the length of radius (calculated on $\alpha, \beta$ and $\gamma$ ); the value of the "center angle" of the curve of Spee (calculated on the radius), of the angle of inclination of the fossa (measured directly on the skull), and of the articular basio-nasal angle (measured directly on the skull); also the gnathic index and the dental index, both measured directly on the skull and calculated for each individual. The name of each species is given at the head of the table. The arrangement of individual records within each table was made according to the diminishing value of the "center angle" of the curve of Spee. The numbers entered were all rounded and the mean values for each measurement are averaged according to the columns.

Table 17 gives for Primates the mean values of $\alpha, \beta$, and $\gamma$, the mean length of radius of the circle, the mean value of the "center angle" of the curve of Spee, the mean value of the inclination angle of the fossa, the mean value of the articular basio-nasal angle, and the mean values of the gnathic and dental indices for each species. The arrangement 
of species within the table was made according to the diminishing value of the "center angle" of the curve of Spee. The figures given in the table were all rounded.

Table 18 gives for Artiodactyla the mean values of $\alpha, \beta$ and $\gamma$, the mean length of radius of the circle, the mean value of the "center angle" of the curve of Spee, the mean value for the angle of the fossa,

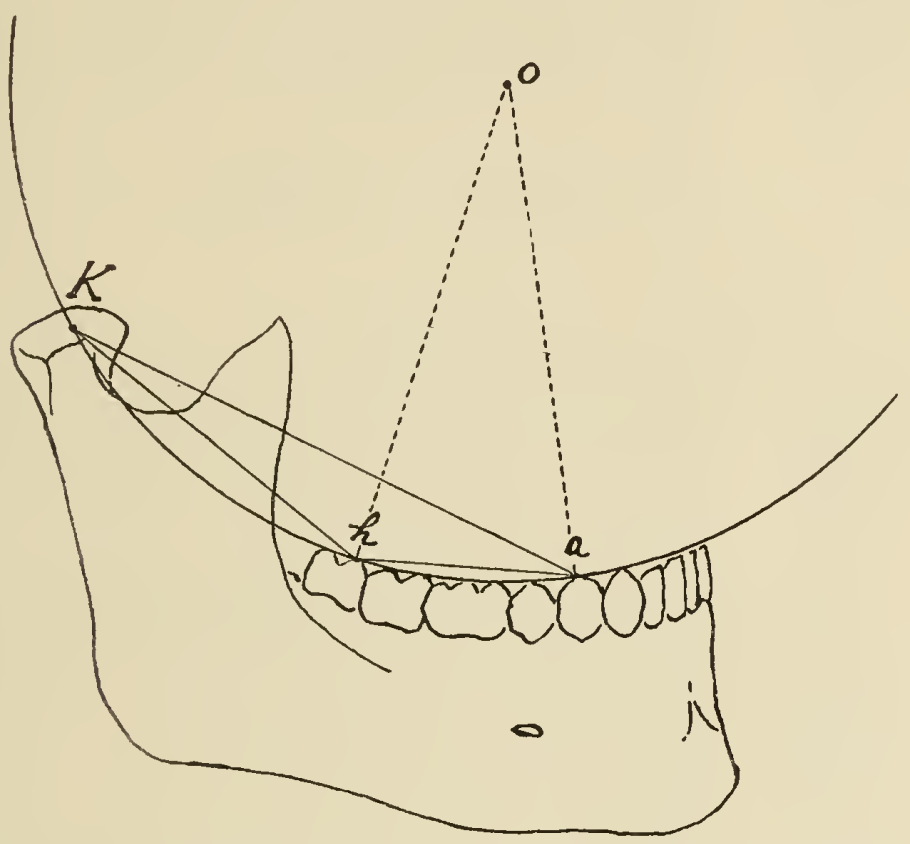

Frg. 4. Diagram Illustrating the Curve of Spee and also the "Center Angle"

$K$, middle point of the anterior face of the articular surface of the condyle; $a$, buccal cusp of the first bicuspid; $h$, mesio-buccal cusp of the third molar; $o$, center of the circle containing the curve of Spee; aoh, the "center angle."

the mean value of the articular basio-nasal angle, and the mean values of the gnathic and dental indices for each species. The arrangement of species within the table was made according to the diminishing value of the "center angle" of the curve of Spee. The figures given in the table were all rounded. 
TABLES $2-16$

A Summary of the Data Ortained from the Measurements of the Skulls of the Animals Designated in Table 1

TABLE 2

Simia satyrus (orang utan)

\begin{tabular}{|c|c|c|c|c|c|c|c|c|c|}
\hline NOMBER OF SPECIMEN & $\alpha$ & $\beta$ & $\gamma$ & RADIOS & $\begin{array}{l}\text { CENTER } \\
\text { ANGLEE }\end{array}$ & \begin{tabular}{|c|c} 
INCLI- \\
NATION \\
ANGLE \\
OF \\
FOSSA \\
MANDIB- \\
OLARIS
\end{tabular} & \begin{tabular}{|l} 
ARTICD- \\
LAR \\
BASIO- \\
NASAL \\
ANGLE \\
\end{tabular} & $\begin{array}{c}\text { GNATHIC } \\
\text { INDEX }\end{array}$ & $\begin{array}{l}\text { DENTAI } \\
\text { INDEX }\end{array}$ \\
\hline & & & & & degrees & degrees & degrees & & \\
\hline 7064 & 4.6 & 7.4 & 10.1 & 5.5 & 48.8 & 26.5 & 25.5 & 151 & 57 \\
\hline 2172 & 4.4 & 6.9 & 10.3 & 6.7 & 38.0 & 29.0 & 18.5 & 143 & 58 \\
\hline 2170 & 4.1 & 7.3 & 10.3 & 6.6 & 36.6 & 30.5 & 22.8 & 148 & 55 \\
\hline 5646 & 4.7 & 6.4 & 10.4 & 8.0 & 34.3 & 12.3 & 33.5 & 155 & 62 \\
\hline 2222 & 4.3 & 6.6 & 10.2 & 7.4 & 34.2 & 17.8 & 20.5 & 140 & 53 \\
\hline 1563 & 4.2 & 7.5 & 11.0 & 8.4 & 29.2 & 11.8 & 23.5 & 163 & 54 \\
\hline 2223 & 4.6 & 7.6 & 11.6 & 9.5 & 28.2 & 20.5 & 31.5 & 159 & 60 \\
\hline Average. & 4.4 & 7.1 & 10.6 & 7.4 & 35.6 & 21.2 & 25.2 & 151 & 54 \\
\hline
\end{tabular}

TABLE 3

Homo (man)

\begin{tabular}{r|r|r|r|r|r|r|r|r|r}
\hline 15640 & 3.8 & 5.4 & 8.5 & 6.0 & 36.6 & 31.8 & 33.5 & 103 & 49 \\
15613 & 4.0 & 5.9 & 9.2 & 6.7 & 34.8 & 26.8 & 38.3 & 97 & 42 \\
800 & 3.9 & 6.0 & 9.3 & 6.8 & 33.4 & 34.5 & 36.7 & 99 & 48 \\
15774 & 3.6 & 4.9 & 8.2 & 6.9 & 30.4 & 42.0 & 42.5 & 105 & 48 \\
15586 & 4.1 & 5.2 & 8.9 & 7.9 & 30.1 & 32.5 & 38.3 & 102 & 49 \\
15863 & 3.6 & 5.7 & 8.8 & 7.1 & 29.4 & 33.5 & 34.0 & 99 & 47 \\
5419 & 3.8 & 6.3 & 9.5 & 7.5 & 29.0 & 35.5 & 36.5 & 100 & 45 \\
15803 & 3.9 & 5.6 & 9.1 & 8.4 & 27.2 & 28.8 & 35.8 & 105 & 46 \\
$Z^{*}$ & 3.5 & 6.6 & 9.5 & 7.5 & 26.9 & 32.8 & 31.5 & 101 & 43 \\
15689 & 3.5 & 6.2 & 9.2 & 7.8 & 26.0 & 43.0 & 35.8 & 98 & 41 \\
$15779 \dagger$ & 3.5 & 5.6 & 8.6 & 7.0 & 26.0 & & & 98 & \\
15700 & 3.3 & 5.7 & 8.7 & 7.5 & 25.5 & 41.5 & 36.5 & 104 & 45 \\
4237 & 3.7 & 6.4 & 9.6 & 9.3 & 23.0 & 32.5 & 38.5 & 101 & 43 \\
4284 & 3.6 & 5.8 & 9.1 & 9.4 & 22.1 & 27.5 & 40.0 & 100 & 43 \\
\hline Average........ & 3.7 & 5.8 & 9.0 & 7.6 & 28.6 & 34.1 & 36.7 & 101 & 45 \\
\hline
\end{tabular}

* This specimen belongs to Dr. Stotsenburg.

† The frontal portion of the occipital foramen of this specimen was lost, so that the determination of the articular basio-nasal angle and the gnathic and dental indices could nøt be obtained.

TABLE 4

Hylobates milleri (gibbon)

\begin{tabular}{c|c|c|c|c|c|c|c|c|c}
\hline 3666 & 2.2 & 3.6 & 5.6 & 4.8 & 26.5 & 2.0 & 23.8 & 121 & 40 \\
12074 & 2.1 & 3.3 & 5.2 & 5.2 & 23.3 & 9.0 & 29.0 & 122 & 41 \\
699 & 2.1 & 3.4 & 5.3 & 5.3 & 23.3 & 3.0 & 28.3 & 118 & 39 \\
690 & 2.1 & 3.2 & 5.2 & 5.8 & 21.5 & 7.0 & 26.3 & 119 & 39 \\
6157 & 2.2 & 3.0 & 5.1 & 6.6 & 19.1 & 4.3 & 28.5 & 118 & 42 \\
\hline Average......... & 2.1 & 3.3 & 5.3 & 5.5 & 22.8 & 5.1 & 27.2 & 120 & 40 \\
\hline
\end{tabular}


TABLES 2-16-Continued

TABLE 5

Macacus cynomolgus (macaque monkey)

\begin{tabular}{|c|c|c|c|c|c|c|c|c|c|}
\hline NUMBER OF SPECIMEN & $\alpha$ & $\beta$ & $\gamma$ & RADIUS & $\begin{array}{l}\text { CENTER } \\
\text { ANGLEE }\end{array}$ & $\begin{array}{c}\text { INCLI- } \\
\text { NATION } \\
\text { ANGLE } \\
\text { OF } \\
\text { OFSSA } \\
\text { MANDIB- } \\
\text { ULARIS }\end{array}$ & $\begin{array}{c}\text { ARTICU- } \\
\text { LAR } \\
\text { BASIO- } \\
\text { NASAL } \\
\text { ANGLE }\end{array}$ & $\begin{array}{c}\text { GNATHIC } \\
\text { INDEX }\end{array}$ & $\begin{array}{l}\text { DENTAX } \\
\text { INDEX }\end{array}$ \\
\hline & & & & & degrees & degrees & degrees & & \\
\hline 1891 & 2.2 & 4.0 & 6.0 & 5.9 & 22.3 & 9.0 & 36.5 & 129 & 45 \\
\hline 1893 & 2.3 & 3.9 & 6.0 & 5.9 & 22.0 & 8.8 & 31.8 & 138 & 48 \\
\hline 1889 & 2.3 & 3.9 & 6.3 & 6.3 & 21.0 & 7.3 & 34.5 & 139 & 51 \\
\hline Average... & 2.3 & 3.9 & 6.0 & 6.0 & 21.8 & 8.4 & 34.3 & 135 & 48 \\
\hline
\end{tabular}

TABLE 6

Nasalis larvatus (Kahaŭ monkey)

\begin{tabular}{c|c|c|c|c|c|c|c|c|c}
\hline 2261 & 2.5 & 3.9 & 6.1 & 5.9 & 24.8 & 4.8 & 33.5 & 120 & 50 \\
1834 & 2.6 & 3.5 & 6.0 & 7.5 & 20.4 & 18.3 & 29.3 & 120 & 53 \\
6156 & 2.8 & 3.3 & 6.0 & 8.3 & 19.2 & 0.0 & 34.5 & 127 & 54 \\
2263 & 2.6 & 3.1 & 5.6 & 8.7 & 17.5 & 2.5 & 38.0 & 121 & 51 \\
2267 & 2.6 & 3.2 & 5.6 & 8.7 & 17.1 & 4.5 & 36.8 & 123 & 53 \\
\hline Average......... & 2.6 & 3.4 & 5.9 & 7.8 & 19.8 & 5.9 & 34.6 & 122 & 52 \\
\hline
\end{tabular}

TABLE 7

Semnopithecus femoralis (sacred monkey-India; hoonoomaŭn)

\begin{tabular}{c|r|r|r|r|r|r|r|r|l}
\hline 2920 & 1.9 & 2.7 & 4.5 & 4.7 & 24.1 & 15.8 & 37.3 & 105 & 40 \\
2657 & 1.9 & 2.8 & 4.6 & 4.5 & 22.6 & 14.0 & 34.8 & 107 & 41 \\
2925 & 2.0 & 2.7 & 4.5 & 5.5 & 20.4 & 8.5 & 35.0 & 105 & 41 \\
3000 & 2.0 & 2.7 & 4.6 & 6.4 & 18.4 & 2.0 & 38.5 & 110 & 44 \\
2923 & 1.8 & 2.7 & 4.4 & 6.0 & 17.7 & 5.3 & 36.0 & 105 & 37 \\
3801 & 1.8 & 2.7 & 4.5 & 6.1 & 17.5 & 21.8 & 37.0 & 105 & 40 \\
2989 & 1.9 & 2.7 & 4.6 & 7.1 & 15.5 & 8.3 & 35.8 & 106 & 41 \\
2660 & 1.8 & 3.0 & 4.7 & 7.3 & 13.9 & 7.0 & 35.0 & 105 & 39 \\
\cline { 5 - 7 } Average ......... & 1.9 & 2.8 & 4.6 & 5.9 & 18.8 & 10.4 & 36.2 & 106 & 40 \\
\hline
\end{tabular}

TABLE 8

Macacus nemestrinus (macaque monkey)

\begin{tabular}{c|r|r|r|r|r|r|r|r|r}
\hline 5660 & 2.9 & 4.0 & 6.7 & 7.5 & 21.5 & -5.3 & 48.8 & 140 & 57 \\
5652 & 2.8 & 4.5 & 7.1 & 8.5 & 18.8 & 12.8 & 45.5 & 153 & 60 \\
5872 & 2.5 & 5.0 & 7.3 & 8.5 & 16.8 & 6.1 & 44.5 & 139 & 50 \\
5861 & 2.7 & 4.0 & 6.7 & 12.3 & 12.5 & 0.5 & 46.3 & 134 & 55 \\
5860 & 2.9 & 4.5 & 7.3 & 14.1 & 11.9 & 0.3 & 41.8 & 147 & 55 \\
\hline Average.......... & 2.7 & 4.4 & 7.0 & 10.2 & 16.3 & 2.8 & 45.4 & 143 & 55 \\
\hline
\end{tabular}


TABLES 2-16-Continued

TABLE 9

Fiber zibethicus (muskrat)*

\begin{tabular}{|c|c|c|c|c|c|c|c|c|c|}
\hline NUMBER OF SPECIMEN & $\alpha$ & $\beta$ & $\gamma$ & RADIUS & $\begin{array}{l}\text { CENTER } \\
\text { ANGLE }\end{array}$ & \begin{tabular}{|} 
INCLI- \\
NATION \\
ANGLE \\
OF \\
FOSSA \\
MANDIB- \\
ULARIS
\end{tabular} & $\begin{array}{c}\text { ARTICU- } \\
\text { LAR } \\
\text { BASIO- } \\
\text { NASAL } \\
\text { ANGLE }\end{array}$ & $\begin{array}{l}\text { GNATHIC } \\
\text { INDEX }\end{array}$ & $\begin{array}{l}\text { DENTAL } \\
\text { INDEX }\end{array}$ \\
\hline & & & & & degrees & desrees & degrees & & \\
\hline 5889 & 1.6 & & & 3.4 & 27.7 & & 21.5 & 132 & 33 \\
\hline 5884 & 1.6 & & & 3.5 & 25.6 & & 20.0 & 133 & 34 \\
\hline $5902 \dagger$ & 1.5 & & & 3.5 & 25.3 & & & & \\
\hline 5921 & 1.5 & & & 3.6 & 24.7 & & 21.3 & 136 & 33 \\
\hline $5903 \dagger$ & 1.5 & & & 3.6 & 24.5 & & & & \\
\hline 5918 & 1.5 & & & 3.7 & 23.2 & & 24.0 & 131 & 34 \\
\hline 5916 & 1.5 & & & 3.7 & 23.1 & & 19.8 & 145 & 34 \\
\hline 5915 & 1.4 & & & 3.7 & 22.3 & & 21.0 & 127 & 33 \\
\hline $5908 \dagger$ & 1.4 & & & 3.6 & 21.6 & & & & \\
\hline 5883 & 1.6 & & & 4.2 & 21.3 & & 20.0 & 133 & 36 \\
\hline Average...... & 1.5 & & & 3.6 & 23.9 & & 21.1 & 134 & 34 \\
\hline
\end{tabular}

* The degrees of inclination of the fossa are not given for this species because the temporo-mandibular articulation of this animal has no tuberculum articulare; consequently, the determination of the degree of inclination of the fossa would be of no value in this relation.

$\dagger$ The occipital bone including the occipital foramen were lost from these specimens, so that the angle of inclination of the fossa, the articular basio-nasal angle, and gnathic and dental indices could not be determined. The average values for each of these angles, therefore, were obtained from seven other specimens.

TABLE 10

Rhinoceros

\begin{tabular}{|c|c|c|c|c|c|c|c|c|c|}
\hline 4661 & 13.8 & 17.4 & 30.7 & 23.3 & 38.4 & 31.5 & 5.8 & 142 & 56 \\
\hline \multicolumn{10}{|c|}{$\begin{array}{c}\text { TABLE } 11 \\
\text { Porcus babyrussa (babirusa) }\end{array}$} \\
\hline 4773 & 6.1 & 7.9 & 13.3 & 11.2 & 31.3 & 28.8 & 13.5 & 205 & 57 \\
\hline
\end{tabular}

TABLE 12

Rangifer larandus (caribou)

\begin{tabular}{c|r|r|r|r|r|r|r|r|l}
\hline 5479 & 7.4 & 9.2 & 16.4 & 14.6 & 29.5 & 13.0 & 21.3 & 214 & 65 \\
5484 & 7.7 & 10.4 & 17.5 & 17.2 & 26.1 & 16.0 & 17.5 & 188 & 56 \\
5477 & 7.7 & 9.3 & 16.5 & 17.2 & 26.0 & 17.8 & 24.0 & 211 & 62 \\
5487 & 7.3 & 10.2 & 16.9 & 16.6 & 25.4 & 20.8 & 16.5 & 216 & 59 \\
5485 & 7.1 & 10.5 & 17.0 & 16.3 & 25.2 & 14.5 & 26.0 & 217 & 54 \\
5480 & 7.6 & 12.0 & 18.9 & 19.1 & 23.3 & 17.3 & 24.3 & 218 & 57 \\
5475 & 7.4 & 9.6 & 16.6 & 18.9 & 22.6 & 10.8 & 25.0 & 250 & 66 \\
\hline Average.......... & 7.5 & 10.2 & 17.0 & 17.1 & 25.5 & 15.7 & 22.1 & 218 & 60 \\
\hline
\end{tabular}


TABLES 2-16-Continued

TABLE 13

Camelus bactrianus (bactrian camel)

\begin{tabular}{|c|c|c|c|c|c|c|c|c|c|}
\hline NUMBER OF SPECIMEN & $\alpha$ & $\beta$ & $\gamma$ & RADIUS & $\begin{array}{l}\text { CENTER } \\
\text { ANGLEE }\end{array}$ & $\mid \begin{array}{c}\text { INCLI- } \\
\text { NATION } \\
\text { ANGLE } \\
\text { OF } \\
\text { FOSSA } \\
\text { MANDIB- } \\
\text { ULARIRIS }\end{array}$ & $\begin{array}{c}\text { ARTICU- } \\
\text { LAR } \\
\text { BASIO- } \\
\text { NASAL } \\
\text { ANGLE }\end{array}$ & 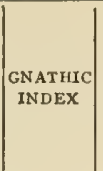 & $\begin{array}{l}\text { DENTAL } \\
\text { INDEX }\end{array}$ \\
\hline & & & & & degrees & degrees & degrees & & \\
\hline 5657 & 10.6 & 14.0 & 23.6 & 22.1 & 27.9 & 30.0 & 9.0 & 179 & 66 \\
\hline 6266 & 10.2 & 13.7 & 23.3 & 25.9 & 22.7 & 19.0 & 13.5 & 176 & 66 \\
\hline Average. . & 10.4 & 13.9 & 23.5 & 24.0 & 25.3 & 24.5 & 11.3 & 178 & 66 \\
\hline
\end{tabular}

TABLE 14

Dicotyles sp. (peccary)*

\begin{tabular}{c|r|r|r|r|r|l|l|l|l}
\hline 2199 & 5.9 & 4.3 & 9.9 & 10.5 & 32.6 & & 36.0 & 126 & 42 \\
6202 & 6.0 & 4.3 & 10.2 & 15.6 & 22.8 & & 33.5 & 180 & 63 \\
$6207 \dagger$ & 6.0 & 3.7 & 9.6 & 16.5 & 20.9 & & & & \\
7451 & 5.8 & 4.2 & 9.8 & 17.2 & 19.2 & & 33.0 & 184 & 61 \\
\hline Average......... & 5.9 & 4.1 & 9.9 & 15.0 & 23.9 & & 34.2 & 163 & 55 \\
\hline
\end{tabular}

* The degree of the inclination angle of the fossa is not given because the temporomandibular joint of this animal is a ginglymus.

$\dagger$ The upper incisors and both the first and second bicuspids were lost from this specimen, so that the line of articulation, and consequently, the inclination angle of the fossa, the articular basio-nasal angle, and the dental index, could not be determined.

TABLE 15

Lama huanacho (guanacho)

\begin{tabular}{l|l|l|l|l|l|l|l|l|l}
\hline 5632 & 5.5 & 10.5 & 15.4 & 13.6 & 23.4 & 67.5 & 18.8 & 171 & 46 \\
\hline
\end{tabular}

TABLE 16

Didelphys marsupialis (opossum)*

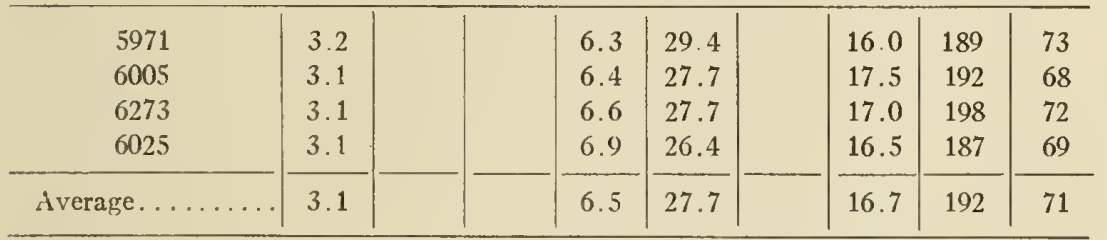

* The degree of the inclination angle of the fossa was not given because the temporomandibular joint of this animal is a ginglymus. 
TABLES 17 AND 18

A Summary of the Mean Values Given in Tables 2-16

TABLE 17

Primates

\begin{tabular}{|c|c|c|c|c|c|c|c|c|c|}
\hline NAME OF SPECIES & $\alpha$ & $\beta$ & $\gamma$ & 总 & 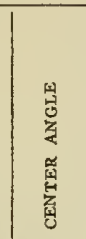 & 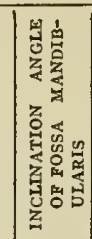 & 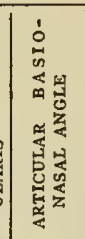 & 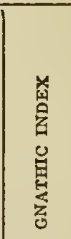 & 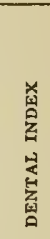 \\
\hline & & & & & degrees & os desrees & s degrees & & \\
\hline Simia satyrus. . & 4.4 & 7.1 & 10.6 & 7.4 & 35.6 & 21.2 & 25.2 & 151 & 54 \\
\hline $\operatorname{Man} \ldots \ldots \ldots \ldots$ & 3.7 & 5.8 & 9.0 & 7.6 & 28.6 & 341 & 36.7 & 101 & 45 \\
\hline Hylobates mülleri. . & 2.1 & 3.3 & 5.3 & 5.5 & 22.8 & 5.1 & 27.2 & 120 & 40 \\
\hline Macacus cynomolgus. . & 2.3 & 3.9 & 6.0 & 6.0 & 21.8 & 8.4 & 34.3 & 135 & 48 \\
\hline Nasalis larvatus..... & 2.6 & 3.4 & 5.9 & 7.8 & 19.8 & 5.9 & 34.6 & 122 & 52 \\
\hline Semnopithecus femoralis. & 1.9 & 2.8 & 4.6 & 5.9 & 18.8 & 10.4 & 36.2 & 106 & 40 \\
\hline Macacus nemestrinus ... & 2.7 & 4.4 & 7.0 & 10.2 & 16.3 & 2.8 & 45.4 & 143 & 55 \\
\hline
\end{tabular}

TABLE 18

Artiodactyla

\begin{tabular}{|c|c|c|c|c|c|c|c|c|c|}
\hline Porcus babyrussa ........... & 6.1 & 7.9 & 13.3 & 11.2 & 31.3 & 28.8 & 13.5 & 205 & 57 \\
\hline Rangifer tarandus. . & 7.5 & 10.2 & 17.0 & 17.1 & 25.5 & 15.7 & 22.1 & 218 & 60 \\
\hline Camelus bactrianus. & 10.4 & 13.9 & 23.5 & 24.0 & 25.3 & 24.5 & 11.3 & 178 & 66 \\
\hline Dicotyles sp....... & 5.9 & 4.1 & 9.9 & 15.0 & 23.9 & & 34.2 & 163 & 55 \\
\hline Lama huanacho. . & 5.5 & 10.5 & 15.4 & 13.6 & 23.4 & 67.5 & 18.8 & 171 & 46 \\
\hline
\end{tabular}

V. DETERMINATION OF THE INCLINATION OF THE FOSSA MANDIBULARIS

It has been claimed by Spee that there exists a close dynamical relation between his curve and the inclination of the fossa, and a similar view has been held by some other authors. I have thought it desirable to examine this matter somewhat in detail.

To study the inclination of the fossa it is first of all important to decide just what portion of the fossa should be taken. Since the purpose of the determination of the inclination of the fossa is to provide data for the discussion of the relation between this inclination and the movement of the jaw, and also between the former and the curve of Spee, the area of articulation within the fossa should be used for the determination of the inclination. This area extends from the 
middle portion of the posterior wall of the fossa to the anterior portion of the tuberculum articulare, and laterally from the lateral portion of the fossa to the anterior portion of the Glaserian fissure. Furthermore, this area presents its greatest willth at the transitional portion of the anterior wall of the fossa to the tuberculum articulare.

It is evident that when the occlusion of the jaws is in the so-called "resting bite," the upper anterior portion of the condyle rests on the anterior wall of the fossa, that is, on the concavity of the area of articulation mentioned above, separated only by the meniscus (interarticular cartilage), while the posterior aspect of the articular surface

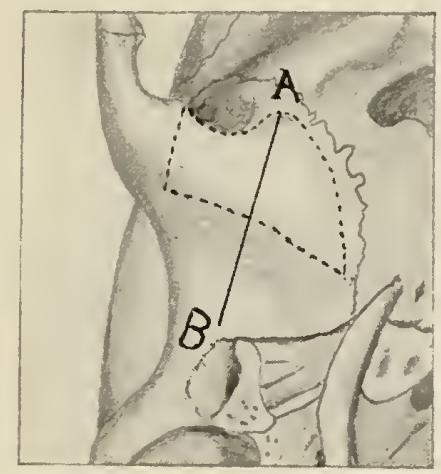

Fig. 5. Drawing Showing, in Dotted Lines, the Area Over Which the Upper Anterior Portion of the Articular Surface of the Condyle Slides

Showing the line $A B$ drawn from the anterior margin of the area to the top of the processus postglenoidalis.

of the condyle is not in contact with the wall of the fossa. If the forward excursion of the lower jaw while in sliding contact starts from the resting bite, the condyle slips downward and forward to the crest of the tuberculum articulare in contact with the concavity of the area. In other words, in the case of sliding contact, the sliding between the condyle and the fossa by the forward excursion of the lower jaw is done principally in the concavity of the area.

It is now necessary to select a base line from which the angle of the inclination may be determined. Tomes and Dolamore ('01) selected a line parallel to the line drawn from the anterior nasal spine to the floor of the external auditory meatus, while Walker and Gyși 
(1895) selected the line of occlusion. ${ }^{3}$ I selected the line of articulation, i.e., the line which is tangent to both the morsal surface of the superior central incisors and the disto-buccal cusp of the upper second molar, because the line selected by Tomes and Dolamore does not seem to me to be related to the occlusion, and the line selected by Walker and Gysi has the disadvantage that it must be determined from the lower jaw.

My next attempt was to obtain the sectional surface along the median line of the fossa, as well as the line of articulation, projected on a sheet of paper. This was accomplished by the following method.

To obtain the sectional surface along the median line of the fossa I have followed the method adopted by Tomes and Dolamore. These authors however did not state the exact portion of the fossa taken, so in order to show the sectional lateral view of the fossa I endeavored to determine the total length from the anterior margin of the area of articulation to the top of the processus post-glenoidalis, which is a small conical process descending in front of the external auditory meatus (fig. 5, $A-B$ ). It was not however always possible to obtain the sectional view of the fossa by actual section from the museum specimens, so a modelling compound (dental) was advantageously used.

A line $(A-B, f i g .5)$ was drawn with a pencil along the fossa of the skull from the anterior margin of the area of articulation on the tuberculum articulare through the fossa to the top of the postglenoid process and then there were marked also with a pencil two points on this line; one at the point where it crosses the posterior margin of the area, and the other at the point where the posterior portion of the crest of the tuberculum articulare passes into the anterior wall of the fossa. Then the fossa was filled with modelling compound under gentle pressure. As soon as the modelling compound hardened, it was removed and cut into two pieces along the pencil line, which had been transferred to it from the skull. One of these pieces was refitted to the fossa again exposing the lateral aspect of the cut surface. A line $(P Q, f i g .6)$ parallel to the line of articulation was then drawn and a deep cut was made with a knife along this line. At the same time the positions of the two marks made before on the fossa were

${ }^{3}$ The line of occlusion is tangent to both the morsil surface of the lower central incisors and the disto-buccal cusp of the lower second molar. 
transferred with a knife to the margin of the modelling compound as is shown in figure 6 ( 1 and 2). The modelling compound was now removed from the fossa and the line of the fossa, including the two knife marks, made for the purpose of obtaining the angle of the inclination of the fossa, as well as the line of articulation, were stamped on a sheet of paper with the aid of painting ink. The value of the
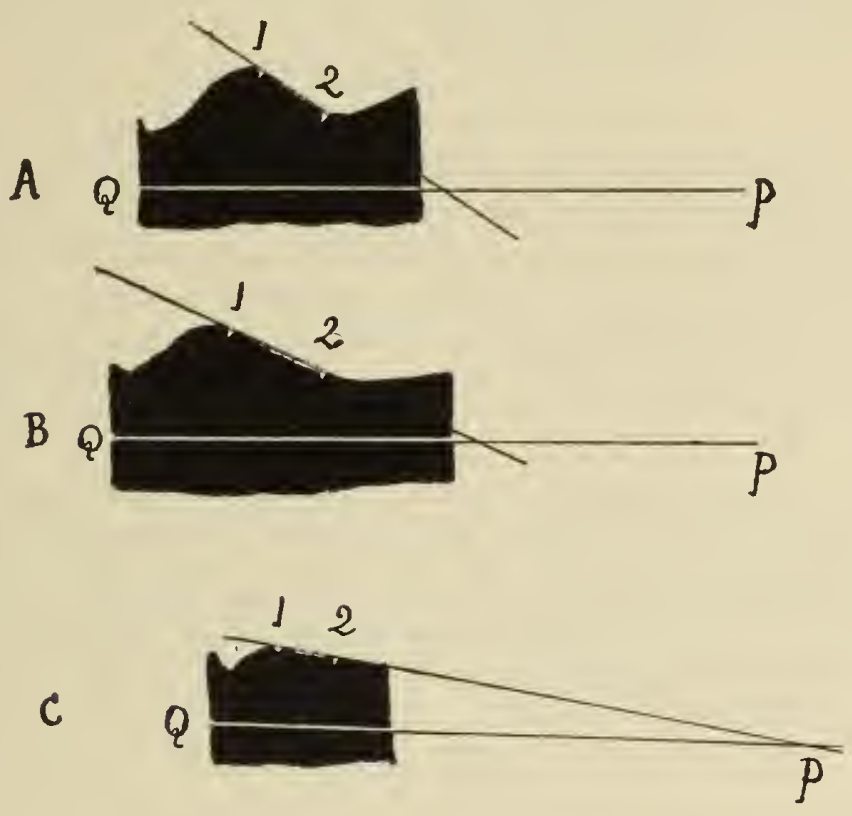

Fig. 6. The Cast, Showns the Outlines of the Glenom Fossa, Obtained by the Method of the Author (Actual Size)

All of the fossae thus outlined were taken from the right side of the skull. The heavy line $(P Q)$ is parallel to the line of articulation. The angle $P Q$ is the angle to be measured. $A$, from the skull of man (Specimen 15613) angle 32 degrees; $B$, from the skull of orang utan (Specimen 7064) angle 24 degrees; $C$, from the skull of Hylobates (Specimen 12074) angle 8 degrees. 1 and 2 are two marks made with a knife, indicating the limits of the area.

angle between the line of articulation and the line which connects the two marks was obtained by the use of a protractor.

Even in the cases of the other animals this same method may be applied either directly or with some slight modification.

The results of these determinations are given in tables 2-16, except 9, 14, and 16. The averages are given in tables 17 and 18 . 
VI. DETERMINATION OF THE DENTAL AND GNATHIC INDICES

\section{Dental index}

"The dental index is the standard of measurement of the size of the teeth to the dimensions of the skull, and may be ascertained by means of the following formula, the length of the distance being marked out by the help of specially contrived calipers:

\section{The length of the teeth $\times 100$ \\ The basio-nasal line}

The length of the teeth means the distance from the mesial aspect of the first bicuspid to the distal aspect of the most posterior molar, all in situ; the basio-nasal line is an imaginary line drawn from a spot on the middle line of the anterior margin of the foramen magnum of the occipital bone (the basion), to the junction of the nasal bones, with the nasal process of the frontal bone in the center of the lower edge of the nasal notch."

(Hopewell-Smith).

I have obtained the data on the dental index for the purpose of comparing the size of teeth of each animal, and at the same time to determine whether or not there exists any relation between this dental index and the curve of Spee. The values of the dental index thus obtained are given in tables 2 to 18 .

\section{Gnathic index}

"The degree of projection of the upper jaw is expressed by the gnathic index, which represents the ratio of the distance between the 'basion' and the 'alveolar point,' to the distance between the 'basion' and the 'nasal point,' i.e., the point of junction of nasal and frontal bones on the middle line. Thus the gnathic index is obtained by ascertaining the value of the

$$
\frac{\text { Basio-alveolar line } \times 100}{\text { Basio-nasal line" }}
$$

(Hopewell-Smith).

My object in obtaining the gnathic index was to test the statement made by Spee that there is some anatomical relation between the prognathy of the jaw and the curve of Spee. The values for this index are given in tables 2 to 18. 
VII. DETERMINATION OF THE ANGLE FORMED BETWEEN THE LINE OF ARTICULATION AND THE BASIO-NASAL LINE

As will be seen later, my own investigations fail to corroborate the statements made by Spee that there exists a close relation between the curve of Spee and the inclination of the fossa, but I have further attempted to find out what the curve of Spee means.

While examining many skulls, in which the curvature of the curve of Spee differs, one relation was found; that is, when the "center angle" was greater, the position of the fossa was correspondingly higher. Furthermore, the fossa and the occipital foramen have approximately the same relative distance from the horizontal plane. I attempted therefore to determine the situation of the occipital foramen in relation to other parts of the skull, and from the data thus obtained it was my hope to determine whether there is any relation between the position of the occipital foramen and the value of the "center angle." I found in the work of Topinard (1878) that Doubenton first determined the situation of the occipital foramen in relation to other parts of the skull. Afterwards Broca attacked the same problem, and proposed two methods. Thus, we have three methods for the determination of the situation of the occipitalforamen; namely, (1) in relation to the angle between the line drawn from the inferior border of the orbit to the opisthion, the opisthio-nasal line (Doubenton); (2) in relation to the angle between the occipital plane and the opisthio-nasal line (occipital angle of Broca); and (3) in relation to the angle between the occipital plane and the basio-nasal line (basilar angle of Broca).

After some practice with these three methods, I came to the conclusion that the last method suited my purpose best. However, to meet my purpose more completely, the occipital plane, which forms one side of the angle in the last method, was substituted by the line of articulation, because the latter line is directly related to the occlusion, while the former plane is not. Thus, I measured the angle $(A C N)^{4}$ between the line of articulation and the basio-nasal line by the following method.

\footnotetext{
"For convenience in description, the abbreviated form "articular basio-angle" is used in place of "the angle between the line of articulation and the basio-nasal line."
} 
The skull was fixed with its basio-nasal line parallel to the horizontal plane by the use of a bar, and another bar was fixed in such a way that it was parallel to the line of articulation. The angle which was thus formed by the intersection of these lines at $C$ was determined by means of a protractor. The data thus obtained are given in tables 2 to 18 .

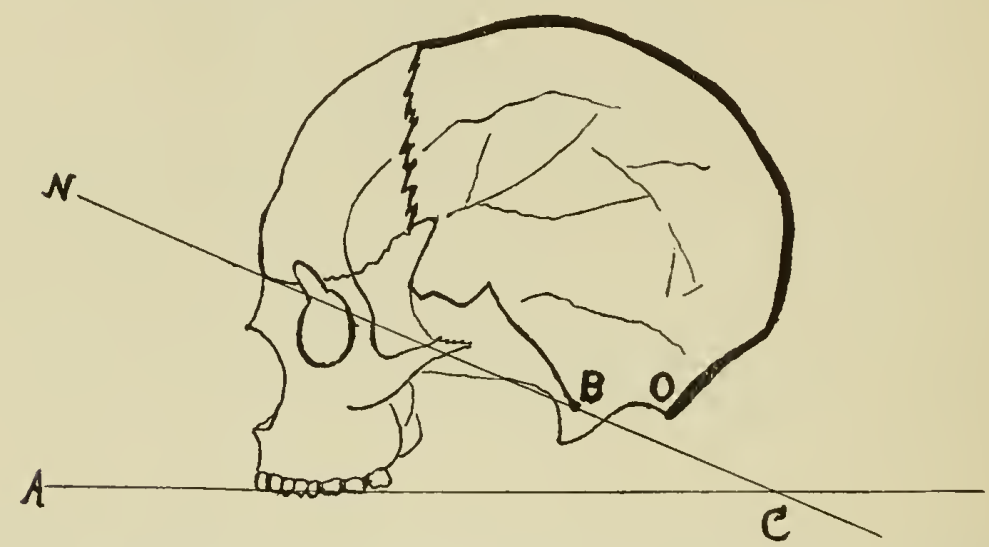

Fig. 7. The Anterior Half Represents the Skoll Intact; the Posterior Half Represents the Skull Open for the Purpose of Showing the Occipital Foramen, and its Two Median Points; Anterior $(B)$ and Posterior $(O)$ $O$, opisthion; $B$, basion. The angle $A C N$ is the articular basio-nasal angle

VIII. COMPARATIVE STUDY OF THE CURVE OF SPEE The author's own data

Before beginning a discussion of the curve of Spee in various animals, it should be stated that the total number of skulls employed for this study was not large. Therefore, the absolute values of the data might be slightly different were the number increased, although it is my belief that any changes subsequently produced would not affect the general conclusions stated in this paper.

For convenience of description and of comparison, the material is classified according to the zoological order of the specimens. For reasons given in a previous section (III), the curves of Spee were compared with each other by comparing the size of the angle at the 
center of the circle lying in the cylinder-surface or the "center angle," and the curvatures of the curves of Spee were compared with each other by comparing the lengths of the radii of the circles to which they belonged. When the data are arranged according to the diminishing values of the "center angle," the relations shown in table 19 are brought out.

From the data in table 19 it is clear that there is no general relation between the value of the "center angle" of the curve of Spee and the

TABLE 19

Values for the "center angle" in various species. Arranged according to the diminishing values for the "center angle"

\begin{tabular}{|c|c|}
\hline NAME OF SPECIES & $\begin{array}{l}\text { VALOE OF } \\
\text { "CENTER ANGLE" }\end{array}$ \\
\hline & degrees \\
\hline 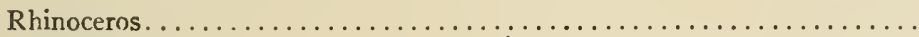 & 38.4 \\
\hline 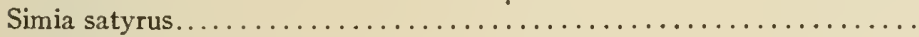 & 35.6 \\
\hline 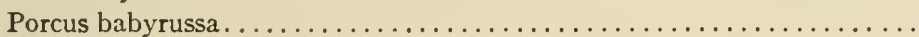 & 31.3 \\
\hline 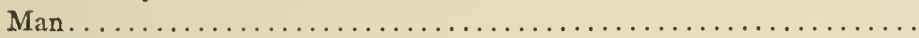 & 28.6 \\
\hline 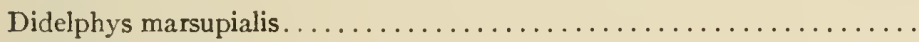 & 27.7 \\
\hline 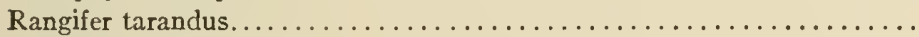 & 25.5 \\
\hline Camelus bactrianus $\ldots \ldots \ldots \ldots \ldots \ldots \ldots \ldots \ldots \ldots \ldots \ldots \ldots$ & 25.3 \\
\hline Dicotyles sp. $\ldots \ldots \ldots \ldots \ldots \ldots \ldots \ldots \ldots \ldots \ldots \ldots \ldots$ & 23.9 \\
\hline 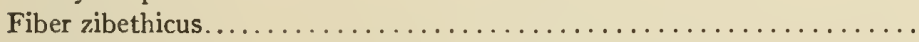 & 23.9 \\
\hline 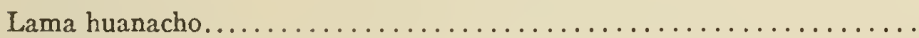 & 23.4 \\
\hline Hylobates mülleri. . . . . . . . . . . . & 22.9 \\
\hline 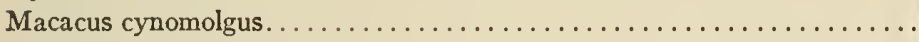 & 21.8 \\
\hline 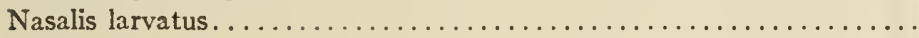 & 19.8 \\
\hline Semnopithecus femoralis....... & 18.8 \\
\hline 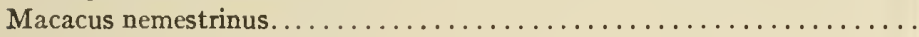 & 16.3 \\
\hline
\end{tabular}

zoological order to which a given species belongs. For example, in Simia satyrus (orang utan) the "center angle" amounts to 35.6 degrees; in Hylobates mülleri it is as small as 22.9 degrees. Both of these are primates. On the other hand, in the Rhinoceros, a perissodactyl, the "center angle" amounts to 38.4 degrees, and in Rangifer tarandus, an artiodactyl, it is 25.5 degrees.

Similarly, we do not find any close relation between the length of the radius of the curve of Spee and the order of mammals to which the species belongs. This fact is shown in table 20 , in which the data are arranged according to the diminishing length of the radius. 
TABLE 20

Data on the length of the radius of the curve of Spee for various species. Arranged according to the diminishing values for the radius

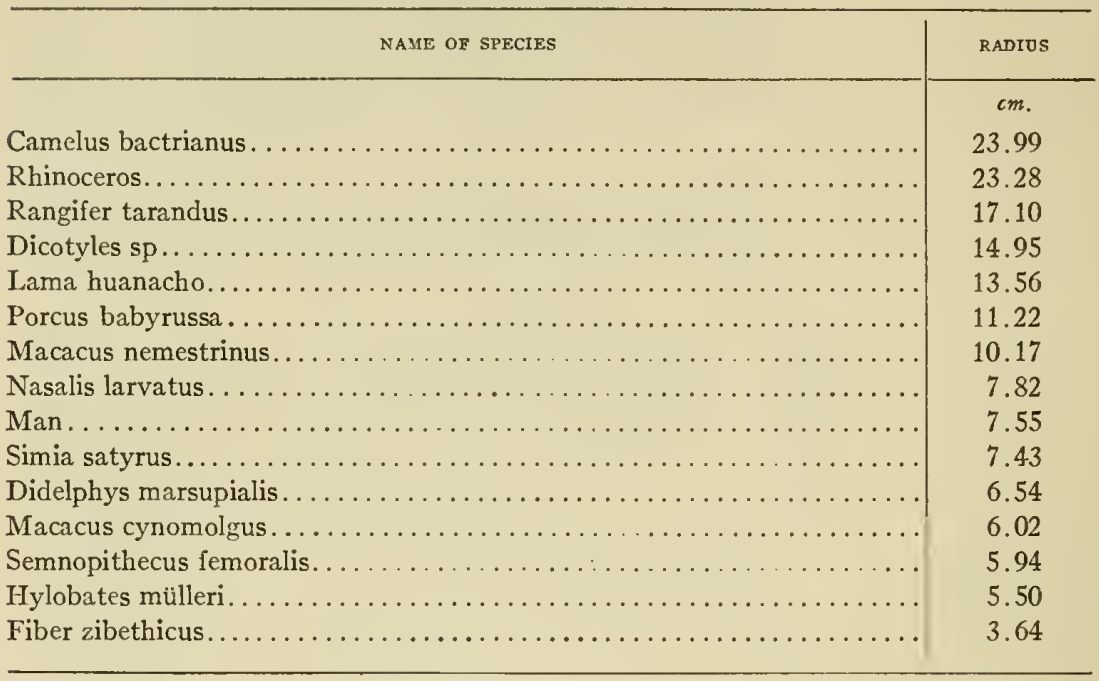

\section{Discussion}

As to the physiological and anatomical significance of the curve of Spee and as to the relation of the curve of Spee to the other parts of the skull, Spee (1890) has put forward the opinions which were briefly summarized at the beginning of this paper, and it is now my intention to reconsider these statements of Spee in the light of my own data.

It is evident, from the data in tables 2 to 18 , that there is no direct relation between the value of the "center angle" of the curve of Spee and the values of $\alpha, \beta$, and $\gamma$, either among different individuals of the same species, or for different species of the same order. Since $\alpha$ has always a fixed relation to the total length of the teeth and $\gamma$ to the length of the lower jaw in the same species, it must be conceded that both the total length of the teeth and of the lower jaw have no relation to the value of the "center angle" of the curve. Furthermore, since it is conceivable that the length of the lower jaw has a fixed relation to both the length and the size of the skull in the same species, we may conclude that there is no correlation between these 
two measurements and the value of the "center angle" of the curve of Spee.

As was indicated in section VI, I measured the dental index (which represents the relation between the size of the teeth and of the skull), with the results given in tables 2 to 16 . From these data I failed,

TABLES 21 AND 22

Data Pertaining to the Dental Index, and the Length of the Radius of the Curve of Spee. Arranged According to the Dominishing Values FOR THE DENTAL INDEX

TABLE 21

Primates

\begin{tabular}{|c|c|c|}
\hline NAME OF SPECIES & DENTAL INDEX & RADIUS \\
\hline & degrees & $c m$. \\
\hline Macacus nemestrinus . . . . . . . . . . . . . . & 55 & 10.17 \\
\hline Simia satyrus $\ldots \ldots \ldots \ldots \ldots \ldots \ldots \ldots \ldots \ldots \ldots \ldots \ldots \ldots \ldots$ & 54 & 7.43 \\
\hline 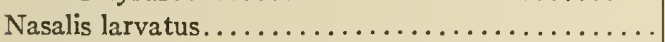 & 52 & 7.82 \\
\hline Macacus cynomolgus . . . . . . . . . . . . . . . & 48 & 6.02 \\
\hline 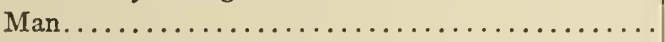 & 45 & 7.55 \\
\hline Semnopithecus femoralis ................. & 40 & 5.94 \\
\hline Hylobates mülleri. . . . . . . . . . . . . . . & 40 & 5.50 \\
\hline
\end{tabular}

TABLE 22

Simia salyrus (orang ulan)

\begin{tabular}{c|c|c}
\hline Simia satyrus (orang utan): & & \\
$5646^{*}$ & 62 & 8.03 \\
2223 & 60 & 9.46 \\
2172 & 58 & 6.68 \\
7064 & 57 & 5.51 \\
2170 & 55 & 6.58 \\
1563 & 54 & 8.38 \\
2222 & 53 & 7.35
\end{tabular}

*Number of the skull of Simia satyrus.

also, to find any relation between that index and the value of the "center angle" of the curve of Spee. For example, in table 2, specimens 5646 and 2222 have nearly the same value for the "center angle" (the former 34.3 degrees, the latter 34.2 degrees) while the dental index of these specimens is different, the former being 62.0 degrees, and the latter 53.0 degrees. I also failed to find any relation between that index and the degree of curvature of the curve of Spee, which 
latter can be inferred from the length of the radius of the curve, as may be seen from the tables. To illustrate the points just mentioned, the data in tables 21 and 22 were arranged according to the diminishing value of the dental index in orang utan and in the primates.

TABLES 23 AND 24

Data Pertaining to the Gnathic Index, and the Length of the Radius of the Curve of Spee. Arranged According to the Diminishing Values FOR THE GNATHIC INDEX

TABLE 23

Primates

\begin{tabular}{|c|c|c|}
\hline NAME OP SPECTES & GNATHIC INDEX & RADIUS \\
\hline & degrees & $\mathrm{cm}$. \\
\hline Simia satyrus $\ldots \ldots \ldots \ldots \ldots \ldots \ldots \ldots$ & 151 & 7.43 \\
\hline Macacus nemestrinus $\ldots \ldots \ldots \ldots \ldots \ldots \ldots \ldots$ & 143 & 10.17 \\
\hline Macacus cynomolgus . . . . . . . . . . . . . & 135 & 6.02 \\
\hline 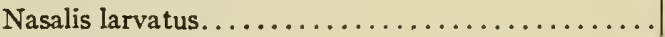 & 122 & 7.82 \\
\hline 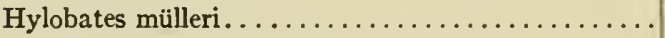 & 120 & 5.50 \\
\hline Semnopithecus femoralis . . . . . . . . . . . . . . . & 106 & 5.94 \\
\hline Man.$\ldots \ldots \ldots \ldots \ldots \ldots \ldots \ldots \ldots \ldots$ & 101 & 7.55 \\
\hline
\end{tabular}

TABLE 24

Simia satyrus (orang utan)

Simia satyrus (orang utan):

\begin{tabular}{l|l} 
& \\
163 & 8.38 \\
159 & 9.46 \\
155 & 8.03 \\
151 & 5.51 \\
148 & 6.58 \\
143 & 6.68 \\
140 & 7.35
\end{tabular}

*Number of the skull of Simia satyrus.

Spee states in his paper (1890) that, in general, the greater the radius of the cylinder-surface on which the occlusal line of the teeth lies, the bigger will be that animal, and the more prognathic the skull. "Der Radius des Cylinder-mantel, auf dem sie liegen, ist im Allgemeinen um so länger, je grösser das Tier, je prognater der Schädel ist." As will be seen from the tables, the results of my measurements show no correlation between the length of the radius, which measures 
the degree of the curvature of the curve of Spee, and the gnathic index, which is taken to represent the degree of prognathy, neither within a species nor within an order. To illustrate these points the data in tables 23 and 24 were arranged according to the diminishing value of the gnathic index in orang utan and in the primates. The data in these tables show that the value of the "center angle" and the degree of curvature of the curve of Spee are independent of the size of the teeth or the size of the skull, or the degree of prognathy.

Relation between the "center angle" of the curve of Spee and the angle of the line of articulation to the basio-nasal line

We notice, from the data in table 17 , that the average measurements given in the primates show a reciprocal relation between the value of the "center angle" of the curve of Spee and of the articular basio-nasal angle (the angle between the line of articulation and the basio-nasal line), if the data for man be omitted, i.e., the greater the "center angle" of the curve, the smaller will be the articular basio-nasal angle, or vice-versa. On the other hand, the average data for artiodactyla (table 18) show no such relation between these two measurements. Curiously enough, when similar data obtained from the different individuals of each species are compared, we do not find a reciprocal relation such as has just been described (see tables 2 to 16). This is true even when the different individuals compared are all of species of primates. Unfortunately, I possess very limited data for the other orders of mammals, and thus I am unable to determine whether or not there is, in other orders, a relation similar to that shown among the primates named in table 17.

If all available individual skulls belonging to the same species within the primates be examined, it will be seen that both the auditory meatus and basion (anterior border of occipital foramen) lie exactly or nearly on the same transverse diameter. As the fossa is always situated close to the auditory meatus, it is evident that the former has also a fixed relation to the basion in respect to the line of articulation. Since the curve of Spee touches the anterior face of the articular surface of the condyle by its backward extension, it follows that the "center angle" of the curve must be greater if the fossa lies 
higher in the skull; and similarly, when the "center angle" is small, the fossa must lie lower in the skull of the same size. Combining these facts, it is conceivable that the relation of the basion to the line of articulation, or the articular basio-nasal angle, is related reciprocally to the "center angle" of the curve of Spee. Whether or not this explanation holds true for the skulls of different sizes cannot be definitely decided until more data are obtained, though it is my firm belief that such a relation is probable.

I stated before that the relation between the value of the "center angle" of the curve of Spee and of the articular basio-nasal angle is reciprocal, when different species of primates, with the exception of man, are arranged in series. In man the "center angle" is as large as 28.6 degrees and occupies the second position in the table, while the articular basio-nasal angle is not correspondingly smaller (36.8 degrees), but holds the sixth position (table 17). For the exceptional relation in man when compared with other primates, the following explanation seems plausible.

If a human skull is compared with the skulls of some other species among the primates, for example with the skull of an orang utan, it will be noted that the relative position of the auditory meatus and of the fossa is remarkably different; namely, when the line of articulation in both skulls is fixed parallel to the same horizontal plane, the auditory meatus of the human skull occupies a position slightly below the fossa, while on the contrary in the orang utan, it occupies a position slightly above it. This difference in the position of the auditory meatus and the fossa in the two species may be related to the factors which we now wish to discuss. If the skull of the orang utan is compared with that of man, it is evident that the latter shows a relatively greater development of the cranium. It therefore follows that in association with the greater growth of the cranial part, the occipital portion suffers a backward and downward extension, and as a consequence both the auditory meatus and the occipital foramen occupy slightly lower positions than in the orang utan. This difference in the relative position of the occipital foramen, and consequently of the basion, in the two forms seems to me to be a factor contributing to the enlargement of the articular basio-nasal angle in man, thus giving him an anomalous position in the table. 
I am unable to suggest a satisfactory explanation for the absence of a similar relation between the "center angle" of the curve of Spee and the articular basio-nasal angle in the artiodactyla, or within the same species in the other orders. As a matter of fact, in a complicated structure like a skull, the anatomical relations which exist among the different parts are exceedingly complex, so that even the relation between the "center angle" of the curve and the articular basio-nasal angle may involve numerous factors which may be different in the different skulls. Again, the fact that in the primates the skulls show a reciprocal relation between the degree of the "center angle" of the curve of Spee and of the articular basio-nasal angle, if the human case be omitted, while in artiodactyla such a relation is absent, might be explained by further tests, but in the present state of our knowledge even a provisional explanation seems futile.

IX. RELATION BETWEEN THE FORM OF THE FOSSA MANDIBULARIS AND THE CURVE OF SPEE

As to the relation of the form of the fossa to the curve of Spee, Spee has given his opinion in different places in his paper (1890). I have compiled, below, his various statements so far as these relate to my own studies:

1. The development of the curve of Spee is dependent upon the presence of the tuberculum articulare.

In other words, the curve of Spee does not exist on a skull which has no tuberculum articulare.

2. In skulls possessing the curve of Spee, when the antero-posterior movement of the lower jaw takes place, the summits of the cusps of the bicuspids and molars of the lower jaw and the condyle move either on an arc of the same circle or on arcs of two circles which are homo-centric: the cusps on one circle, the condyle on the other.

We may deduce from this that the steeper the path of the condyle of the lower jaw during antero-posterior movement, the shorter will be the radius of the cylinder-surface, or vice-versa.

3. There is close relation between the curve of Spee and the sagittal movement of the jaw during mastication.

That is to say, we cannot recognize the curve of Spee on any skull which shows no sagittal movement of the jaw during mastication. 
The results of my study apparently oppose these three conclusions by Spee. I present below the argument for my own views.

As to point one: Spee states that in rodentia and carnivora the curve of Spee is absent. In these forms the tuberculum articulare is also absent, while in the horse, Cervus elephas, Cervus dama, small monkeys and man, which show the curve of Spee, the tuberculum articulare is present. I have examined two species of rodentia, the guinea-pig (Cavia cutleri) and the muskrat (Fiber zibethicus). In the case of the guinea-pig the tuberculum articulare is absent and the animal does not possess the curve of Spee. In fact a line drawn connecting all summits of the buccal cusps of the bicuspids and molars is nearly a straight line. On the other hand, in the case of the muskrat, not only is the curve of Spee evident, but the degree of the curvature is considerable, as can be inferred from the small length of the radius of the circle (table 9), yet this animal does not possess the tuberculum articulare, as it should according to Spee.

In the case of carnivora, my observations agree with those of Spee that the skulls possess neither the curve of Spee nor the tuberculum articulare. It is well known that the temporo-mandibular joint in carnivora is quite different from that in most of the other mammals. For example, in Felidae the fossa is complete and therefore fits the form of the condyle (an interarticular cartilage being, however, interposed) with such accuracy that only a single motion is possible; consequently, in the process of opening the mouth, any part of the mandible must describe an arc of a single circle, of which the condyle is its center. The term "ginglymus" is used to describe such a joint, as was explained earlier.

All the carnivora examined by me possess the ginglymus joint, and the curved line touching the summits of the buccal cusps of the bicuspids and molars represents an undulating curve, as was described in section II in connection with the skull of the raccoon. Again, according to Spee, the tuberculum articulare is absent in all carnivora. However, in the cases of Didelphys marsupialis (opossum) representing the marsupials, and of Dycotyles sp. (peccary) representing the artiodactyla, I found that, although these animals possess a temporo-mandibular joint resembling that of carnivora, and consequently the tuberculum articulare is absent, nevertheless the curved 
line of the bicuspids and molars corresponds to an arc of a circle. These findings lead me to reject the generalization of Spee that where the tuberculum articulare is absent, the curve of Spee is also absent.

As to point two: Before discussing this conclusion (2) by Spee, I present here my own results, which show the relation between the inclination of the fossa to the line of articulation and the length of the radius of the curve of Spee; also, the relation between the inclination of the fossa and the value of the "center angle" of the curve of Spee.

Throughout tables 2 to 8,10 to 13 , and 15 , it will be found that there are no reciprocal relations between these two measurements among individuals belonging to the same species. For example, in table 3, specimen 15640 has the smallest length of radius, which amounts to $6.00 \mathrm{~cm}$., while the inclination angle of the fossa is 31.8 degrees, the value of which is below the average ( 34 degrees) for the entire series. On the other hand, specimen 15689 has a radius of $7.8 \mathrm{~cm}$., yet the corresponding degree of the inclination angle is 43 degrees. Condensed tables 17 and 18, which give the average values for the inclination of the angle of the fossa and the average length of the radius, for each species in the primates and artiodactyla, show also that there is no reciprocal relation between those two measurements among species belonging to the same order. For example, in table 17, Hylobates mülleri has the smallest length of the radius which signifies the possession of the greatest curvature, yet the greatest angle of inclination is given by man.

The data on the inclination of the angle of the fossa were obtained, as stated in section IV, from direct measurements on the prepared skull, thus disregarding the interarticular cartilage which is interposed between the condyle and the fossa. If therefore this cartilage were taken into consideration, the relation between these two measurements would be somewhat different. Fortunately, however, the meniscus in the fossa of man and of the other mammals is not so thick as to modify the general relations already obtained. In the case of man, for example, the meniscus in the backward portion of the fossa measures $3 \mathrm{~mm}$. in thickness, that in the middle portion 1 to $2 \mathrm{~mm}$., and it is interposed between the anterior face of the articular surface of the condyle and the articular surface of the fossa. Finally, the 
forward portion measures $2 \mathrm{~mm}$. in thickness and covers the tuberculum articulare.

Thus it is evident that, so far as my own observations go, the statement that the steeper the path of the condyle of the lower jaw during antero-posterior movement, the shorter will be the radius or vice versa, cannot be accepted.

The statement by Spee that the summits of the cusps of the bicuspids and molars of the lower jaw, and the condyle, will move on the same circle or on two homo-centric circles-the cusps on one circle, the condyle on the other-during antero-posterior movement, will now be discussed from the standpoint of mechanics. For convenience I shall make a brief statement concerning the mechanism of the antero-posterior movement of the lower jaw in man. Starting from the so-called "resting bite" of the jaw, we analyse the anteroposterior movement of the lower jaw into the following two components according to the motion of the incisors:

1. A downward and forward movement of the inferior central incisors (hereafter called the first part of the movement);

2. An upward and forward movement of the same (hereafter called the second part of the movement). In the first part of the movement, a point $\left(j_{\mathrm{I}}\right.$, fig. 8) on the morsal surface of the lower central incisors moves downward and forward parallel to the lingual surface of the upper central incisors (moving from point $j_{\mathrm{i}}$ to $j_{\mathrm{ii}}, f i g .8$ ), because, following the protrusion of the jaw in the condition of sliding contact, the point $\left(j_{\mathrm{i}}\right)$ slides closely on the lingual surface of the upper central incisors. The remainder of the lower jaw, and consequently the center of the condyle, will move in the same direction, i.e., downward and forward parallel to the lingual surface of the upper central incisors. This first part of the movement has been called, by some, "parallel displacement (parallele Verschiebung)."

According to Eltner this first part of the movement is a "combined displacement (combinierte Verschiebung)" rather than a parallel displacement, because during protrusion the condyle rotates around the axis connecting the centers of the condyles, and at the same time rotates around the axis connecting the centers of the tuberculum articulare on both sides, while the lower jaw as a whole moves downward and forward. The condyle as a whole should therefore 
not move parallel to the lingual surface of the upper central incisors, but its path should be a short arc of a circle. However, it seems to me that, even granting that in this instance the lower jaw moves on a circle, nevertheless the distance moved is but a few millimeters,

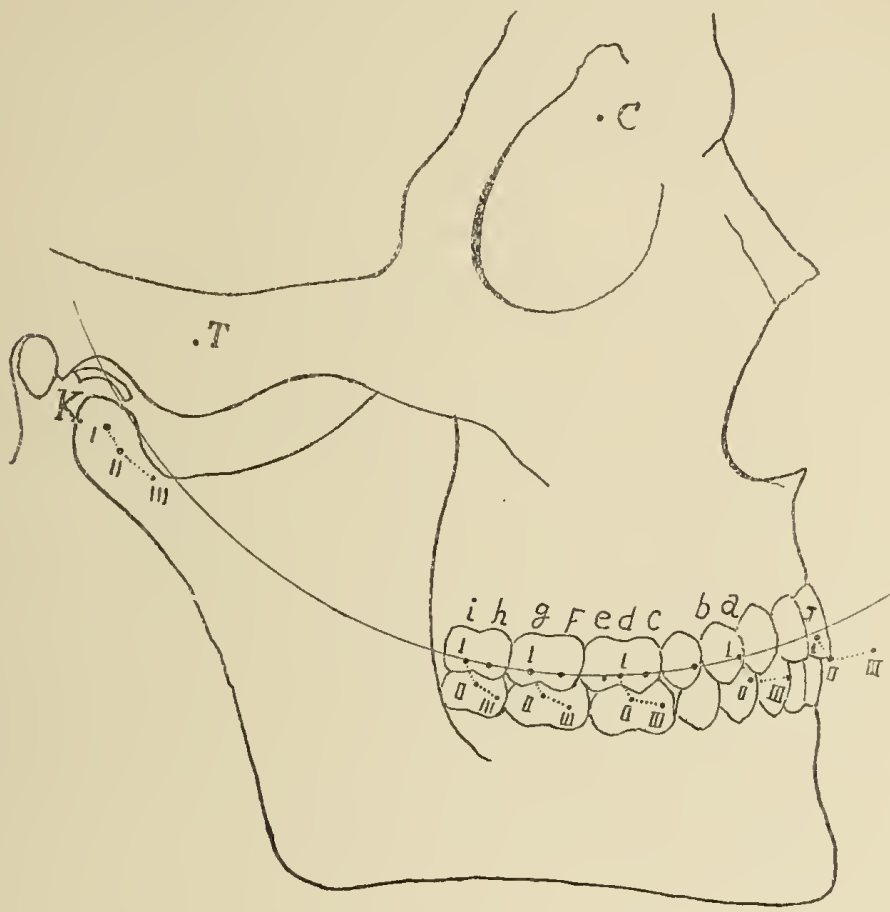

Fig. 8. Diagrau Illustrating the Direction of the Movement of the Lower JaW in the First and Second Parts of the Movement of Protrusion, and also the Relation of this Movement to the Curve of Spee

-........

I II III curve, showing the course of movement of each buccal cusp of the lower bicuspids and molars. ( $j)$ : A point on the morsal surface of the lower incisors and $(K)$ the middle point of the condyle. To avoid confusion in the drawing, curves are not given for each point, but only for $j, a, d, g, i$, and $K$. T... transverse axis passing through each tuberculum mandibularis.

so that under these circumstances the path of the center of the condyle could be regarded as a straight line. My observations on the skulls which exhibit ideal occlusion induce me to conclude that all points in the lower jaw move downward and forward as a whole, thus producing the movement of the "parallel displacement." 
In the second part of the movement, a point $(j)$ on the morsal surface of the lower central incisors moves upward and forward, starting from the position of so-called "edge-to-edge bite" (from $j_{\mathrm{ii}}$ to $j_{\mathrm{iii}}$ ), and at the same time the center of the condyle moves forward and downward along the articular surface of the tuberculum articulare (from $K_{\mathrm{ii}}$ to $K_{\mathrm{iii}}$ ), so that the lower jaw as a whole rotates slightly around the axis represented by the line connecting the centers of the two condyles. This second part of the movement represents a combined displacement.

It appears therefore that the antero-posterior movement of the lower jaw in the state of sliding contact is a "parallel displacement" in the first part, and a "combined displacement" in the second part, of the movement; so that when the lower jaw is protruded, starting from the resting bite, or is retracted, starting from the position of protrusion, it might move either along a curve touching the summits of the buccal cusps of the bicuspids and molars (the curve of Spee), or along another curve parallel to this. But, in general, the direction along which the lower jaw moves is downward and forward in the first part and upward and forward in the second part; and thus, although the condyle or the points near it move, in the first part, nearly parallel to the curve of Spee, yet the course of the anterior portion of the jaw, or that further away from the condyle, deviates from the curve of Spee, the degree of deviation being proportional to the distance from the condyle.

The above relation may be seen clearly from figure 8 . The line $K_{\mathrm{i}}-K_{\mathrm{ii}}$ along which the condyle moves during the first part of the movement is nearly parallel to the curve of Spee, while the line $a_{i}-$ $a_{\mathrm{ii}}, b_{\mathrm{i}}-b_{\mathrm{ii}}$ etc., along which each cusp moves during the first part, diverges from the curve of Spee, the degree of divergence being smaller as the condyle is approached. Moreover, the curve of $K_{\mathrm{i}}-K_{\mathrm{ii}}-K_{\mathrm{iii}}$, $a_{\mathrm{i}}-a_{\mathrm{ii}}-a_{\mathrm{iii}}, b_{\mathrm{i}}-b_{\mathrm{ii}}-b_{\mathrm{iii}}$. etc., or successive positions occupied by the moving condyle or cusps during the first and second parts, is neither a portion of the curve of Spee nor of a circle homo-centric with it, as is shown in figure 8 .

Finally, in the case of man, it is possible in some instances to slide the lower jaw antero-posteriorly some distance while in contact with the upper jaw. Such a movement of the lower jaw is, however, 
possible only for a short distance, because anteriorly the morsal surface of the lower central incisors strikes the lingual surface of the upper central incisors at once, and posteriorly the head of the condyle strikes the processus postglenoidalis of the fossa at once. The maximum distance along which the lower jaw can travel is about 1 to $2 \mathrm{~mm}$. Therefore, even if we grant that the jaw moves antero-posteriorly along the curve of Spee, it is highly improbable, on account of the short distance of such a movement, that the antero-posterior movement of the jaw has any relation to the curve of Spee, and consequently the existence of the curve of Spee is not associated with any greater efficiency in mastication.

During the course of this investigation it was found that there are some cases in which the jaw cannot perform an antero-pesterior movement such as that just described, owing to the form of the teeth or of the temporo-mandibular joint; nevertheless, the presence of the curve of Spee is evident. For example, Simia satyrus, Hylobates mülleri, Macacus cynomolgus, Nasalis larvatus, Semnopithecus femoralis, Macacus nemestrinus, et. al, cannot perform such antero-posterior movements owing to the form of the teeth; in other words, the teeth of these mammals show ideal occlusion and thus there is no room for such antero-posterior movements when the jaws are in contact. Furthermore, Dicotyles sp., the peccary, and Didelphys marsupialis, the opossum, have a temporo-mandibular joint which is "ginglymus" as already stated, and for this reason they cannot perform such anteroposterior movements at all. Nevertheless in all these mammals the curve of Spee is unmistakably present.

Fick (1911) also opposes the conclusion of Spee for a reason similar to my own, namely, that the distance within which the lower jaw moves antero-posteriorly is too short. Furthermore, he states that when the rotation of the lower jaw takes place around the horizontal axis represented by the line which connects the middle of each orbit, the "coincident sliding (kongruentes Schleifen)" of the total occlusal surface of the teeth does not occur, because the projection of the teeth forms an arc not only upon the sagittal plane, but also upon the horizontal plane, so that when the lower jaw moves antero-posteriorly the occlusal surface of the bicuspids and molars does not slirle coincidently, but the sagittal aspects of the teeth only slide by each other. 
As to point three: Spee (1890) stated that the curve of Spee is found in those classes of mammals in which the tuberculum articulare is present, and that in the same animals the antero-posterior movement of the lower jaw is possible. As examples Spee gives the names of the following animals: horse, Cervus elephas, Cervus dama, small monkeys and man. To these I can add the names of the following animals: Simia satyrus, Camelus bactrianus, and Lama huanacho. Whether or not the antero-posterior movement of the lower jaw is possible for these animals, I am unable to state from my own investigation. Studies have been published in regard to this question in some of these animals, by others, however. Descriptions of the movement of the lower jaw during mastication have been given by Meyer (1865) and by Krabbe (1892). The most entensive observations on this subject are found in the laborious and exhaustive work of Lubosch (1907). The following account is based on the work of Lubosch, unless otherwise stated.

It will be advantageous to discuss the motion of the lower jaw in terms of the following three movements; opening, lateral and anteroposterior movements. In marsupialia and carmwora, the lower jaw performs mastication principally by the opening movement (especially the hinge movement) supplemented by a little lateral movement. In perissodaclyla, besides the opening movement, both the anteroposterior movement and the lateral movement occur, the former however being much greater than the latter. In most artzodactyla, besides the opening, the movement of the lower jaw is principally lateral, although in some, e.g. pig and hippopotamus, the principal movement is antero-posterior with a little lateral movement. In rodentza, besides the opening movement, the principal movement is antero-posterior.

The description of the movements of the lower jaw just given reveals at once the fact that, despite the lack of antero-posterior movement during mastication, the curve of Spee is present in most of the artiodactyla (Lama huanacho, Rangifer tarandus, Camelus bactrianus, etc.) and in the marsupialia (opossum). Furthermore, in the pig, guinea-pig, and rodent, in which the movement of the lower jaw is principally antero-posterior, the line drawn touching the summits of the cusps of the bicuspids and molars does not represent the curve 
of Spee, but is a straight line (see section II). We thus see that, in some of the mammals, the curve of Spee is found irrespective of the presence or absence of the antero-posterior movement of the lower jaw during mastication. It naturally follows that the close relation said, by Spee, to exist between the curve of Spee and the anteroposterior movement of the lower jaw, cannot be accepted without modification.

From the above it is clear that the statements made by Spee that there is close relation between the curve of Spee and the form of fossa, or between the curve of Spee and the antero-posterior movement of the lower jaw during mastication, cannot be accepted, whether we consider them from the standpoint of the mechanism of mastication or from actual tests made on the skull. Moreover, it is clearly indicated by this series of facts that the movements of the lower jaw during mastication in all animals named by Spee, as well as those studied by me, are not the antero-posterior movement only, but rather a mixed motion resulting from a combination of the three components which have been recognized. It follows, therefore, that, in the animals in which the curve of Spee exists, the teeth do not have any greater efficiency as a masticatory organ than in those animals which do not possess the curve of Spee.

It may be pointed out that, although the curve of Spee is often called "the compensating curve" under the erroneous impression that it compensates the movement of the jaw during mastication, yet, as I have already indicated in the preceding section, such compensation, in the sense of Spee, does not take place, and for this reason the use of the term should be discontinued.

\section{SUMMARY}

The main results of the present investigation are indicated in the following findings:

1. The line touching the summits of the buccal cusps of the bicuspids and molars was carefully studied on the skulls of numerous mammals. According to the nature and form of this curved line, three types may be distinguished; namely, (a.) a curved line which corresponds to the arc of a circle with its convexity downwards (the 
curve of Spee); (b) a curved line which, possessing several maxima, resembles an undulating curve; and (c) a type which is best represented by a straight line. The first type may be further divided into two kinds; one in which, in its backward extension in the projection plane, the curved line touches the anterior face of the articular surface of the condyle; another, in which the curved line does not do this.

2. The length of the radius of the circle of which the curve of Spee is a part was selected as a standard for comparison of the curvature of the arc, and the "center angle" which subtends a given length of the curve, was chosen as the standard in comparing the curve of Spee in different mammals. From the data obtained by these two kinds of measurements in several orders of mammals, the following results were calculated.

Of the primates examined, Macacus nemestrinus has the longest radius $(10.17 \mathrm{~cm}$.), Hylobates mülleri has the shortest radius $(5.50$ $\mathrm{cm}$.), and man takes an intermediate position, having a radius of $7.55 \mathrm{~cm}$. Of the artiodactyla, Porcus babyrussa has the shortest radius $(11.22 \mathrm{~cm}$.), while Camelus bactrianus has not only the longest radius $(23.99 \mathrm{~cm}$.) in this order, but also the longest among all the mammals examined.

In the case of the "center angle," the following relations were found: Among the primates, Simia satyrus has the greatest angle (35.6 degrees), Macacus nemestrinus the smallest (16.3 degrees), while man with 28.6 degrees occupies an intermediate position in the order. Among the artiodactyla, Porcus babyrussa has the greatest angle (31.3 degrees), and Lama huanacho the smallest (23.4 degrees). Rhinoceros was found to possess the greatest angle (38.4 degrees) among all the mammals examined.

3. Neither the curvature of the curve of Spee nor the "center angle" of the curve increases or decreases regularly according to the zoological order to which the animal belongs.

4. Neither the curvature nor the magnitude of the "center angle" of the curve of Spee varies proportionately with the size of the teeth, the size of the skull, or the degree of prognathy of the skull.

5. (a) Spee's conclusion that there is a close relation between the radius of the curve of Spee and the inclination of the fossa mandib- 
ularis is not supported, the data on these two measurements failing to indicate a definite relationship (see tables).

(b) The existence of the curve of Spee was established in animals which have the tuberculum articulare, as well as in some animals (e.g., the muskrat) without the tuberculum. Even among animals which have the tuberculum, the teeth do not always exhibit the curve of Spee, but in some cases (e.g., the wild pig) lie in a straight line. Therefore the existence of the curve of Spee is not necessarily associated with the presence of the tuberculum articulare.

(c) Spee's opinion, that the path of the lower jaw during its anteroposterior movement is on the curve of Spee, cannot be accepted. The arguments on this question, from the standpoint of the mechanism of the jaw during mastication, as well as from the morphological examination, are presented in the text. I am therefore inclined to believe that the curve of Spee is not closely related either to the manner of movement of the lower jaw, or to the efficiency of mastication.

6. A reciprocal relation between the value of the "center angle" of the curve of Spee and the value of the angle of the line of articulation to the basio-nasal line (articular basio-nasal angle), was found in the primates, with the exception of man.

7. The real significance, physiological and anatomical, of the curve of Spee is not clear.

\section{LITERATURE CITED}

BREHa, A. C. 1890 Brehm's Tierleben. Leipzig und Wien.

FIck, R. 1911 Handbuch der Anatomie u. Mechanik der Gelenk. dritter Teil, pp. 1-35. Fischer, Jena.

Gysi, A. 1910 The Dental Cosmos, lii, 1. (Being a translation of Professor Gysi's book Beitrag zum Articulationsproblem, published by Hirschwald, Berlin, in 1908, with some practical additions written since its publication).

Hopewell-Smith, A. Dental Anatomy and Physiology. Lea and Febiger, Philadelphia, pp. 168 and 172.

KRABBE, H. 1892 Einige Bemerkungen über die mechanischen Verhältnisse der Kauwerkzeuge und der Kaubewegungen. Deutsch. Zeitschr. f. Tiermedizin u. vgl. Pathologie, xix, 33 .

Luвоsсп, W. $190 \mathrm{C}$ Semon's Forschungsreisen, iii. Jena Zeitschr., pp. 549-606.

Luboscr, W. 1907 Universelle und spezialisierte Kaubewegungen bei Saugetieren. Biol. Zentralbl., xxvii.

Meyer, H. 1865 Das Kiefergelenk. Arch. f. Anat. u. Physiol., pp. 719-731.

Port ANd EUler 1915 Lehrbuch der Zahnheilkunde, pp. 186-207. 
SpeE, F. 1890. Die Verschiebungsbahn des Unterkiefers am Schädel. Arch. f. Anat. u. Physiol., Jahrg. 1890.

Tomes, C. S. AND Dolnmore, W. H. 1901. Some observations on the motions of the mandible. Trans. Odontological Soc. of Great Britain.

Topinard, P. 1878. Anthropology, pp. 52-55. J. B. Lippincott \& Co., Philadelphia. Waiker, W. E. 189.5. The Dental Cusmos, xxxviii, 34. 




\section{Photomount \\ Pamphlet Binder Gaylord Bros. Syracuse, $\mathbf{N} . \mathbf{Y}$. PAl. JAH 21, 1908}




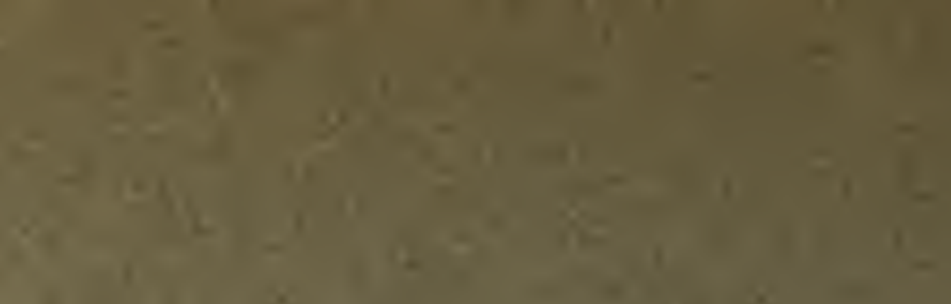

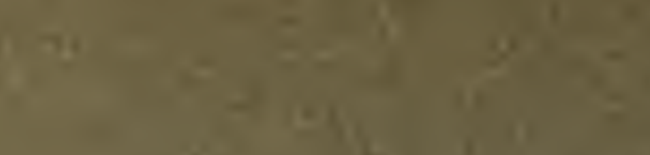

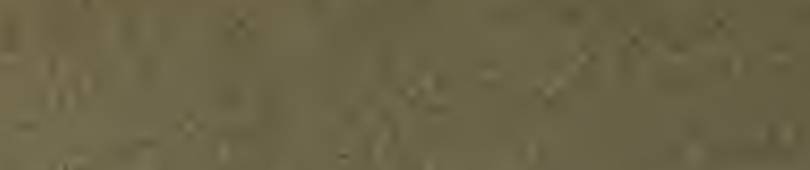

$$
\begin{aligned}
& \text { (1) }
\end{aligned}
$$

(x)

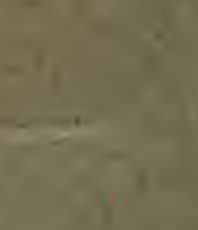

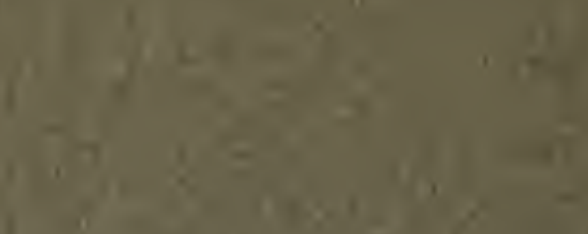

1.1.

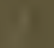

I

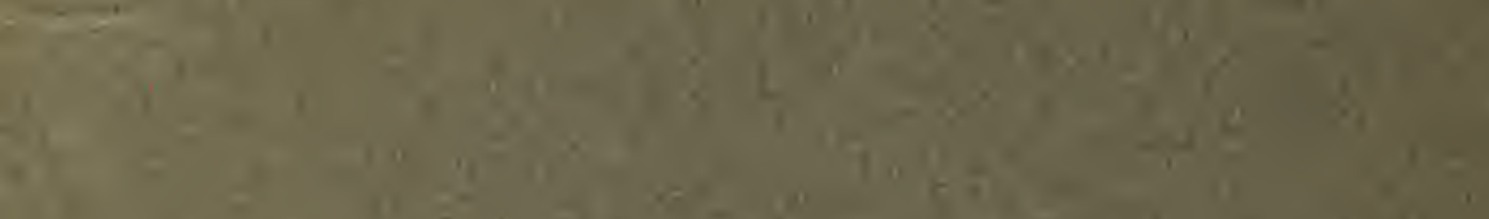

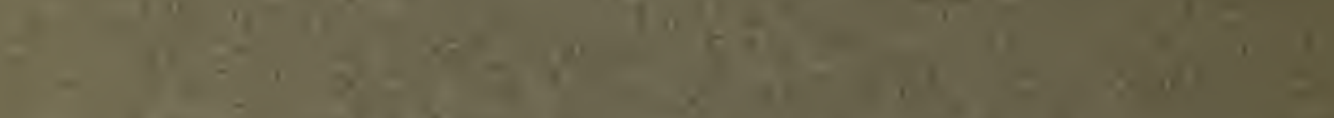

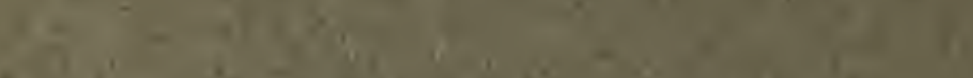

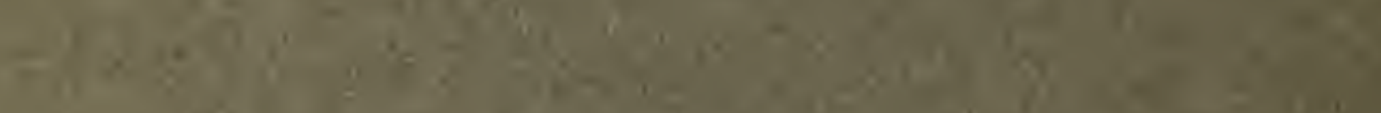

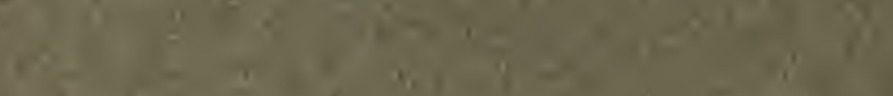

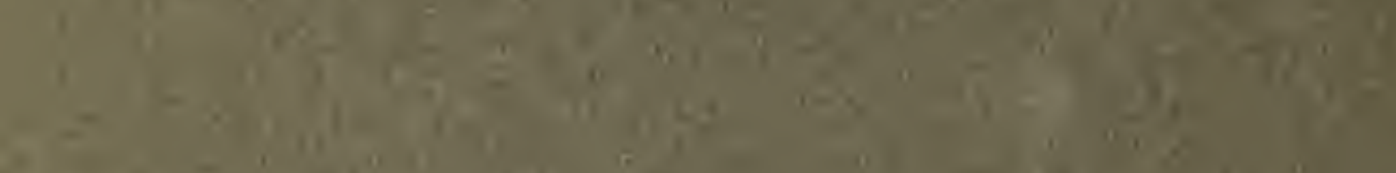

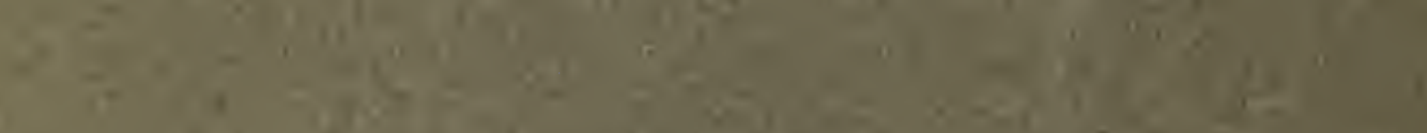

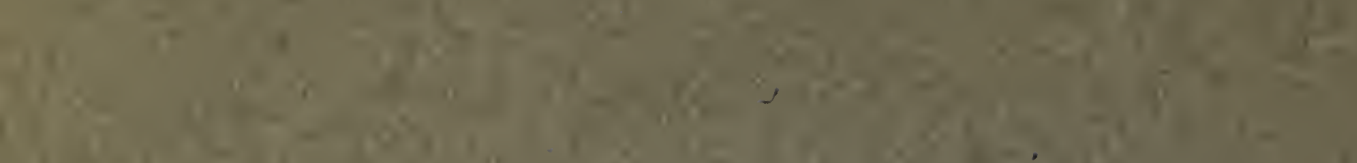

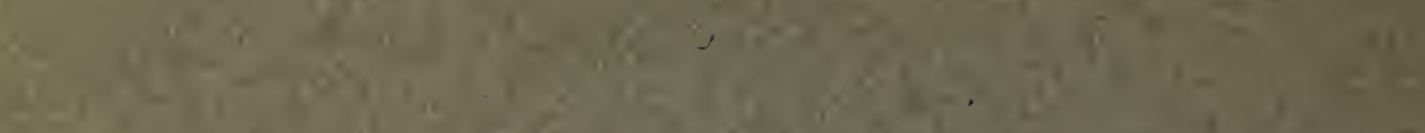

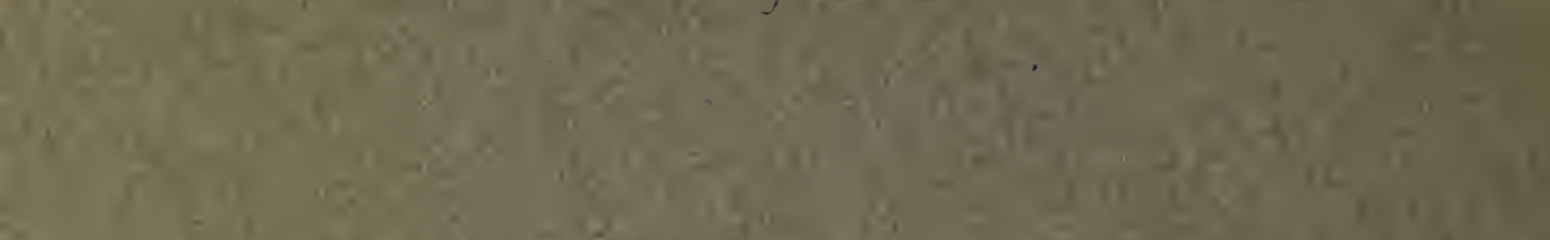

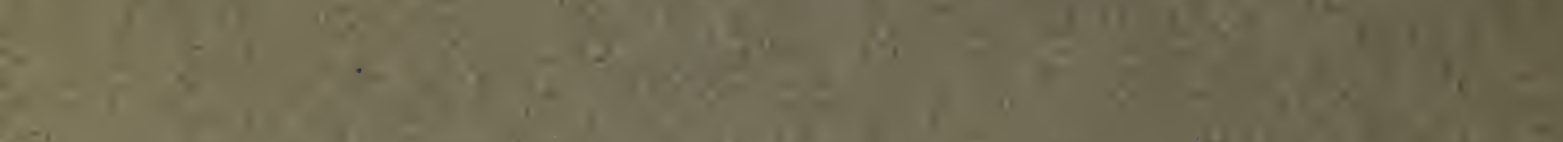

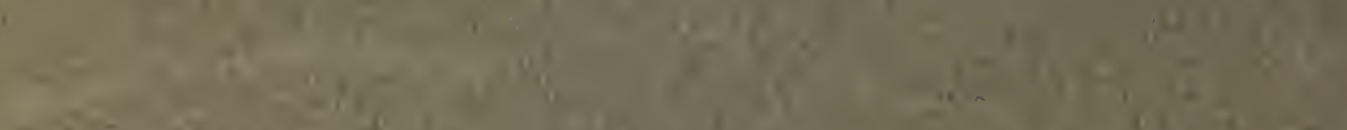

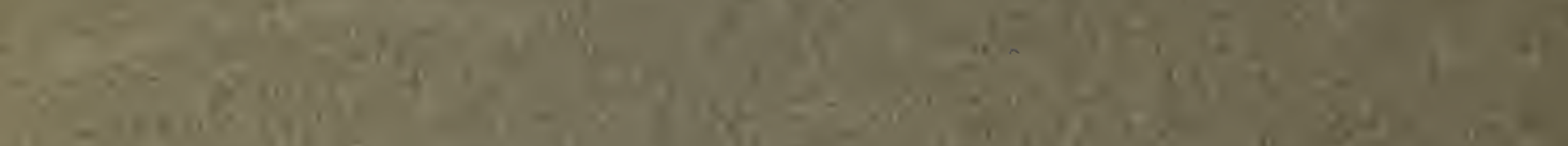

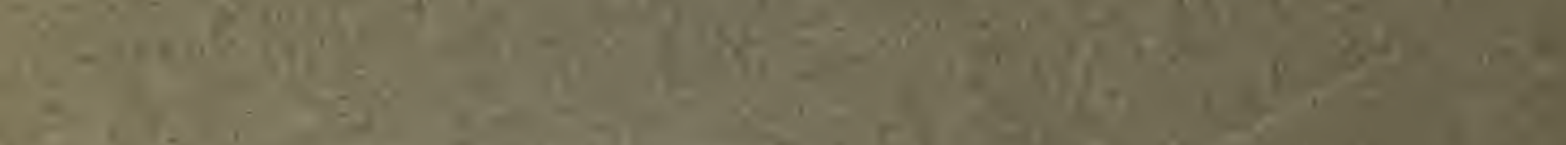

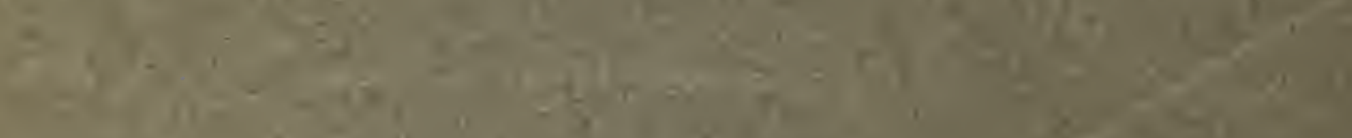

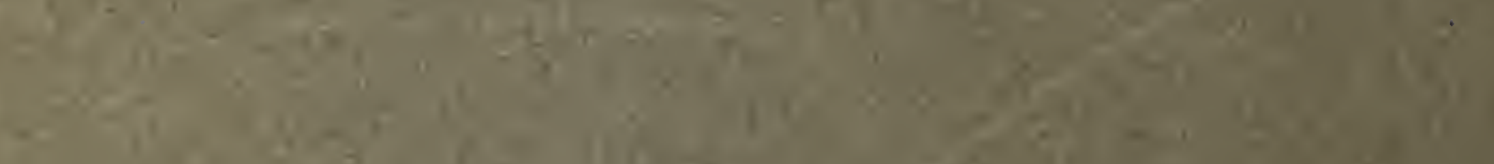

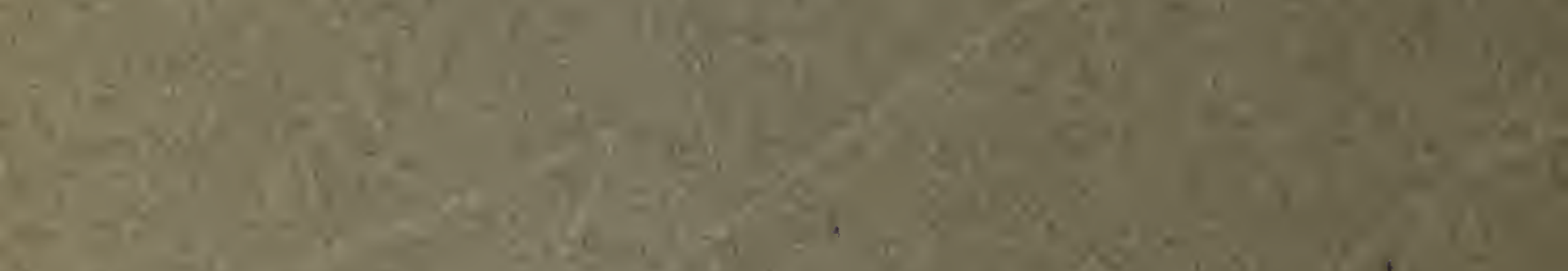

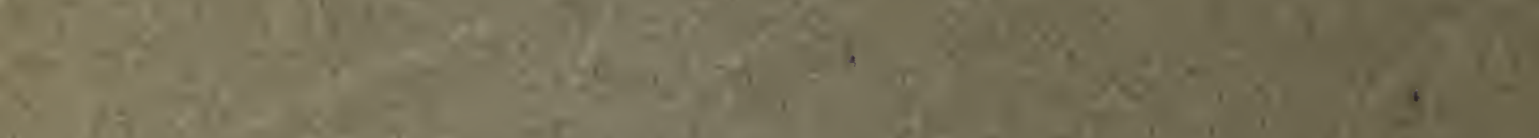

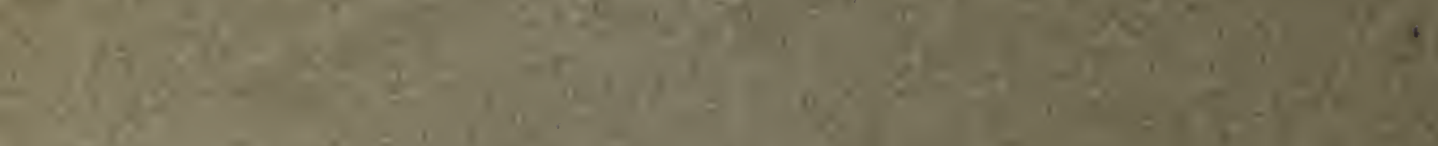

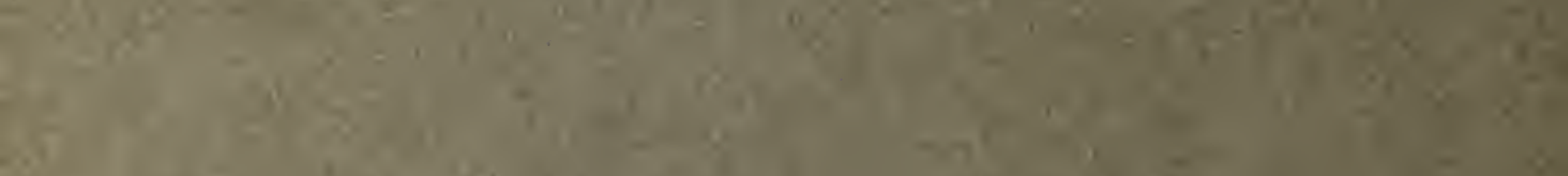

